\title{
The protective effects of neighborhood collective efficacy on British children growing up in deprivation: A developmental analysis
}

\section{Citation}

Odgers, Candice L., Terrie E. Moffitt, Laura M. Tach, Robert J. Sampson, Alan Taylor, Charlotte L. Matthews, and Avshalom Caspi. 2009. the protective effects of neighborhood collective efficacy on British children growing up in deprivation: A developmental analysis. Developmental Psychology 45, no. 4: 942-957. doi:10.1037/a0016162.

\section{Published Version}

doi:10.1037/a0016162

\section{Permanent link}

http://nrs.harvard.edu/urn-3:HUL.InstRepos:33010413

\section{Terms of Use}

This article was downloaded from Harvard University's DASH repository, and is made available under the terms and conditions applicable to Open Access Policy Articles, as set forth at http:// nrs.harvard.edu/urn-3:HUL.InstRepos:dash.current.terms-of-use\#OAP

\section{Share Your Story}

The Harvard community has made this article openly available.

Please share how this access benefits you. Submit a story. 


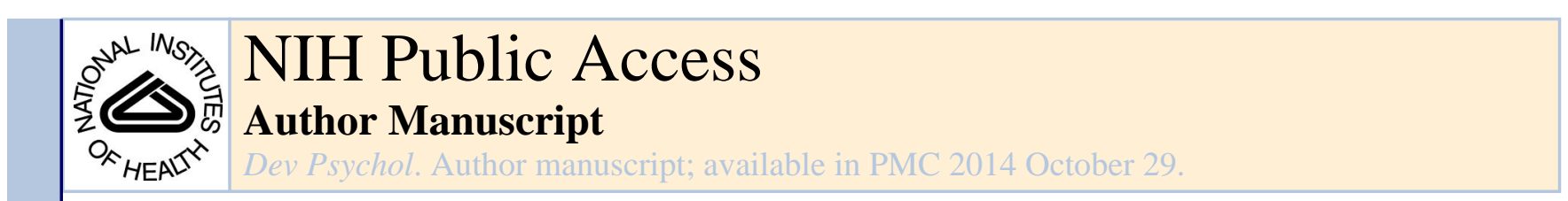

Published in final edited form as:

Dev Psychol. 2009 July ; 45(4): 942-957. doi:10.1037/a0016162.

\title{
The Protective Effects of Neighborhood Collective Efficacy on British Children Growing Up in Deprivation: A Developmental Analysis
}

\author{
Candice L. Odgers, \\ Terrie E. Moffitt, \\ Laura M. Tach, \\ Department of Sociology, Harvard University \\ Robert J. Sampson, \\ Department of Sociology, Harvard University
}

Department of Psychology and Social Behavior, University of California, Irvine

Departments of Psychology and Neuroscience and of Psychiatry and Behavioral Sciences and the Institute for Genome Sciences and Policy, Duke University, and the Social, Genetic, and Developmental Psychiatry Centre, Institute of Psychiatry, King's College London

Alan Taylor,

Social, Genetic, and Developmental Psychiatry Centre, Institute of Psychiatry, King's College London

Charlotte L. Matthews, and

Social, Genetic, and Developmental Psychiatry Centre, Institute of Psychiatry, King's College London

\section{Avshalom Caspi}

Departments of Psychology and Neuroscience and of Psychiatry and Behavioral Sciences and the Institute for Genome Sciences and Policy, Duke University, and the Social, Genetic, and Developmental Psychiatry Centre, Institute of Psychiatry, King's College London

\section{Abstract}

This article reports on the influence of neighborhood-level deprivation and collective efficacy on children's antisocial behavior between the ages of 5 and 10 years. Latent growth curve modeling was applied to characterize the developmental course of antisocial behavior among children in the E-Risk Longitudinal Twin Study, an epidemiological cohort of 2,232 children. Children in deprived versus affluent neighborhoods had higher levels of antisocial behavior at school entry (24.1 vs. 20.5, $p<.001)$ and a slower rate of decline from involvement in antisocial behavior between the ages of 5 and $10(-0.54$ vs. $-0.78, p<.01)$. Neighborhood collective efficacy was negatively associated with levels of antisocial behavior at school entry $(r=-.10, p<.01)$ but only

(C) 2009 American Psychological Association

Correspondence concerning this article should be addressed to Candice L. Odgers Department of Psychology and Social Behavior, 3361 Social Ecology Building II, University of California, Irvine, Irvine, CA 92697-7085. codgers@uci.edu. 
in deprived neighborhoods; this relationship held after controlling for neighborhood problems and family-level factors. Collective efficacy did not predict the rate of change in antisocial behavior between the ages of 5 and 10. Findings suggest that neighborhood collective efficacy may have a protective effect on children living in deprived contexts.

\section{Keywords}

antisocial behavior; collective efficacy; neighborhoods; protective factors; latent growth curve modeling

Youth growing up in deprived neighborhoods are at risk for poor educational, emotional, and health outcomes. Research has consistently linked neighborhood deprivation to problem behaviors such as substance use, teenage childbearing, and conduct disorder in adolescence (Leventhal \& Brooks-Gunn, 2003). However, less is known about how neighborhood-level factors influence antisocial behavior among children. The current study maps the developmental course of children's antisocial behavior from age 5 to age 10 across deprived versus affluent neighborhoods and tests whether neighborhood-level social processes have protective effects on children's development. More specifically, we tested whether neighborhood deprivation influences children's levels of antisocial behavior at school entry or their rate of change in antisocial behavior across time. Moving beyond neighborhood deprivation, we also tested whether the degree of collective efficacy within a neighborhood - the level of social cohesion among neighbors combined with their willingness to intervene on behalf of the common good-had an independent effect on children's developmental course of antisocial behavior. This study is novel in that we (a) focused on a key childhood developmental period for predicting long-term prognosis for antisocial behavior, (b) applied independent state-of-the-art assessments of the neighborhoods in which children live, and (c) asked whether neighborhood-level strengths, such as collective efficacy, protect children growing up in deprivation.

\section{The Developmental Course of Antisocial Behavior During Childhood}

Antisocial behavior consists of aggressive and delinquent acts that result in physical or psychological harm to others or their property (e.g., stealing, lying, and getting into fights). Such behaviors violate the rights of others and, in some cases, violate legal codes. In the present study, we assessed children's antisocial behavior using the Achenbach family of instruments (Achenbach, 1991a, 1991b), which is the most widely used and well-validated assessment scheme for evaluating antisocial behavior problems among children and adolescents. The antisocial behavior construct reported in this article was derived from items from the Delinquent Behavior (e.g., lying or cheating, swearing or using bad language) and Aggressive Behavior (e.g., hot temper, physically attacking people) scales of the Child Behavior Checklist (CBCL) and the Teacher Report Form.

Many children engage in antisocial behavior during early childhood. However, the majority of children reduce their involvement in antisocial behavior as they transition into school settings and move through their primary-school years (Tremblay \& Nagin, 2005): A number of longitudinal studies have documented this normative pattern of decline across childhood 
(Broidy et al., 2003; Coté, Vaillancourt, LeBlanc, Nagin, \& Tremblay, 2006; Nagin \& Tremblay, 1999; Odgers et al., 2007b; Stanger, Achenbach, \& Verhulst, 1997). The mechanisms underlying the decline in antisocial behavior are hypothesized to be rooted in prosocial parenting and socialization by peers and teachers that occur as children make the transition to school contexts. Positive socialization experiences that are reinforced across a child's home, school, and neighborhood are believed to facilitate the development of selfregulation and peer relationship skills, thereby allowing the child to achieve his or her objectives through socially acceptable means (Cairns, Cairns, Neckerman, Ferguson, \& Gariepy, 1989; Tremblay, 2000). Children who fail to develop self-regulation skills are more likely to exhibit externalizing behavior problems (Calkins, 1994; Eisenberg et al., 2000) and, subsequently, are at high risk for continued aggression and related problems (Tremblay, 2004).

Decades of longitudinal research have shown that childhood-onset and persistent antisocial behavior predicts a range of poor outcomes, including depression, substance use disorders, poor physical health, relationship difficulties, self-harm behaviors, poor educational attainment, and social welfare dependency (Fergusson, Horwood, \& Ridder, 2005; KimCohen et al., 2003; Kratzer \& Hodgins, 1999; Moffitt, Caspi, Harrington, \& Milne, 2002; Odgers et al., 2007a, 2008; Piquero, Daigle, Gibson, Leeper-Piquero, \& Tibbetts, 2007; Wiesner, Kim, \& Capaldi, 2005). Thus, there is great interest in identifying individual, familial, and neighborhood-level factors that may influence antisocial behavior during childhood.

\section{Are Neighborhood Factors Related to Children's Developmental Course of Antisocial Behavior?}

To date, research has focused primarily on child- and family-level factors related to persistent antisocial behavior (Moffitt, 2006), with less attention paid to the contexts in which children live and develop (Earls \& Carlson, 2001). In particular, very little is known about whether neighborhood factors can help to explain why some children's antisocial behavior does not desist across childhood. Neighborhood research has also traditionally focused on structural characteristics of the neighborhood, such as deprivation, and it is now well established that deprived neighborhoods can be a harmful place for children and adolescents (Brooks-Gunn, 1997; Mather \& Rivers, 2006). However, recent advances in the ecological assessment of social environments, or ecometrics (Raudenbush \& Sampson, 1999), are creating new possibilities for moving beyond measuring neighborhood structure. In particular, new methodologies are providing a window for exploring the mechanisms through which neighborhood-level social processes may influence behavior and health (Sampson, Morenoff, \& Gannon-Rowley, 2002). A key construct that has emerged from this new science is collective efficacy, which refers to the level of social cohesion among neighbors combined with their willingness to intervene on behalf of the common good (Sampson, Morenoff, \& Earls, 1999; Sampson, Raudenbush, \& Earls, 1997). The level of collective efficacy within a community is not reducible to the characteristics of individual members of their respective communities. Rather, collective efficacy has been described as a combination of both informal social control and social cohesion and reflects the willingness 
of community members to look out for each other and intervene when trouble arises, especially on behalf of the community's youth. This group-oriented behavior is believed to constrain deviant behaviors and to reflect a community's ability to extract resources from the larger infrastructure and mobilize social capital within a community (Sampson et al., 1997).

A growing number of studies have found that neighborhood collective efficacy partially mediates the association of neighborhood structural factors, namely deprivation, with crime and other measures of well-being (Sampson et al., 2002). That is, even after the influence of collective efficiacy has been taken into consideration, neighborhood deprivation remains a direct predictor of many outcomes (Morenoff, Sampson, \& Raudenbush, 2001). These findings are important as they demonstrate the need to consider well-validated measures of both neighborhood deprivation (a structural dimension of neighborhoods) and neighborhood collective efficacy (a process dimension of neighborhoods) when assessing "neighborhood effects." In the present study, we obtained independent assessments of both neighborhood deprivation and collective efficacy to directly test whether either, or both, of these neighborhood-level dimensions influence the developmental course of children's antisocial behavior. In particular, we were interested in testing the theoretical notion that neighborhood collective efficacy protects children who are growing up in deprived neighborhoods.

\section{Can We Reliably Measure Neighborhood-Level Social Processes?}

After surveying over 40 peer-reviewed studies between 1990-2001, Sampson and colleagues concluded that neighborhood-level social processes can be measured reliably and effectively or, simply put, that "ecometrics works" (Sampson et al., 2002, p. 222). The collective efficacy measure used in this study has been validated in a number of large-scale studies, many of which have used multiple methods to assess neighborhood features, including postal surveys, systematic social observation (e.g., videotaping of neighborhood blocks), and quasi-experimental methods (e.g., "lost letter drop" experiment; Kaplan, 2007; Sampson \& Raudenbush, 1999; Sampson et al., 1997).

Despite significant advances in the assessment of neighborhoods over the last decade, integrating neighborhood-level assessments into developmental research is a challenging task. First, the majority of research examining child outcomes, with a few notable exceptions (e.g., the Project on Human Development in Chicago Neighborhoods; http:// www.icpsr.umich.edu/PHDCN), has relied exclusively on either census-level data or parental reports of neighborhood context. The exclusive use of census-level data narrows investigators to a focus on neighborhood demography and limits analyses to a social address model (Bronfenbrenner, 1986) versus testing how neighborhood-level social processes may influence child outcomes. Similarly, a reliance on mother's reports of neighborhood-level social processes is not ideal, as it typically results in the mother reporting on both the outcome (child's behavior) and the predictor (neighborhood factors).

Second, to date, neighborhood-level research has been a "small effect size" enterprise. The independent correlation between neighborhood factors and individual-level health outcomes typically falls between .10 and .20 (Leventhal \& Brooks-Gunn, 2000). Nonetheless, the 
prevention implications of such findings continue to intrigue scientists and policy analysts (Hawkins \& Catalano, 1992), resulting in calls to begin defining the "black box" of neighborhood effects. More specifically, there is a need to isolate how specific dimensions of neighborhoods are related to individual-level health outcomes (Cummins, Curtis, DiezRoux, \& Macintyre, 2007; Macintyre, Ellaway, \& Cummins, 2002) and to develop models that can elucidate mediating and developmental pathways of neighborhood-level influence on behavior and health (Duncan \& Raudenbush, 2001; Sampson et al., 2002). With these challenges in mind, the present study obtained independent assessments of neighborhood collective efficacy, a prime candidate for understanding how specific neighborhood-level factors may be translated into child outcomes.

There are a number of reasons why neighborhood-level collective efficacy could help to explain children's developmental course of antisocial behavior. First, neighborhood collective efficacy has been identified as an important proximal mechanism for understanding a wide range of health outcomes among children and adolescents (Sampson, 2003) including, for example, internalizing disorders (Xue, Leventhal, Brooks-Gunn, \& Earls, 2005) and obesity (Cohen, Finch, Bower, \& Sastry, 2006). Second, neighborhood collective efficacy has shown robust associations with antisocial outcomes among adults, including violent crime (Sampson et al., 1997), partner violence (Browning, 2002), and homicide (Morenoff et al., 2001) and is believed to be a pathway through which neighborhood effects are transmitted. Research also suggests that middle childhood may represent a critical period during which children are at heightened risk for neighborhoodbased effects on antisocial behavior problems (Ingoldsby et al., 2006). Third, as discussed in the next section, neighborhood collective efficacy may be especially relevant for understanding children's antisocial behavior as collective efficacy indexes two processes: (a) informal social control, which may directly reduce antisocial behavior within a community, and (b) social cohesion among neighbors, which is likely to enhance the support available to parents and promote positive parenting practices.

Hypothesis 1: Children growing up in deprived versus affluent neighborhoods will exhibit higher levels of antisocial behavior at school entry (age 5 years) and a slower rate of decline in antisocial behavior between the ages of 5 and 10 years.

Neighborhood deprivation has been consistently linked to poor outcomes among children and adolescents (Brooks-Gunn, 1997), including involvement in antisocial behavior and crime (for a review, see Ingoldsby \& Shaw, 2002). However, to our knowledge, few studies have mapped the developmental course of antisocial behavior among male and female children across deprived versus affluent neighborhoods. In their review of the theoretical models of neighborhood effects on child outcomes, Leventhal and Brooks-Gunn (2000) argued that such developmental frameworks are missing — and required—in neighborhood research. On the basis of prior research, we expected children in deprived versus affluent neighborhoods to have higher initial levels of antisocial behavior. However, we also expected that children in deprived neighborhoods would exhibit a slower rate of decline in their antisocial behavior across childhood because opportunities for positive socialization out of such behaviors would be limited. 
Hypothesis 2: Neighborhood-level collective efficacy is expected to be associated with less antisocial behavior at school entry and is also expected to be associated with socialization away from antisocial behavior (faster rate of decline) between the ages of 5 and 10 years.

Neighborhoods with high levels of collective efficacy were expected to have a positive influence on children's development and should facilitate the successful socialization of children into school and other community contexts. The influence of neighborhood-level collective efficacy on children's antisocial behavior was expected to begin very early in life as trust and cohesion within the community influence children's development indirectly by, for example, increasing the amount of social support available to parents, enhancing parents' feelings of safety and trust in their communities, and having a positive effect on parents' mental health and well-being. Neighborhood-level collective efficacy may also exert social control on parents' behavior by establishing local expectations regarding the use of overly harsh or abusive parenting practices or setting community tolerance levels toward domestic violence. Thus, we expected high levels of collective efficacy to be associated with lower rates of antisocial behavior by children at school entry (negative relationship).

The positive influence of collective efficacy on children's antisocial behavior was expected to continue as children move through primary school and begin to have more direct interactions with their neighborhoods (e.g., at school, in playgrounds). During this period, high levels of social cohesion, combined with the presence of invested adults who are willing to intervene and prevent antisocial behavior in the community, should facilitate and reinforce the development of prosocial behavior among children while deterring the use of antisocial behavior across school and neighborhood contexts. Therefore, high levels of collective efficacy were expected to predict faster socialization of children away from antisocial behavior between the ages of 5 and 10, with children in neighborhoods with high collective efficacy exhibiting the steepest declines in antisocial behavior across this period (negative relationship). It has also been suggested that neighborhood factors may exert stronger effects as children move through middle childhood; therefore, we conducted sensitivity analyses to test the influence of collective efficacy on antisocial behavior at ages 5,7 , and 10 .

Hypothesis 3: Neighborhood-level collective efficacy will have a stronger effect on children's antisocial behavior in deprived versus affluent neighborhood contexts.

Neighborhood deprivation and neighborhood collective efficacy do not necessarily go hand in hand. Indeed, research has shown that collective efficacy mediates the relationship between neighborhood deprivation and mental and physical health outcomes (Cohen et al., 2006; Cohen, Farley, \& Mason, 2003; Sampson et al., 1997; Xue et al., 2005). These findings are important because they illustrate that neighborhood collective efficacy is not synonymous with neighborhood affluence and, moreover, that considering neighborhood structural characteristics in isolation does not tell the entire story regarding neighborhood effects on health.

It is easy to imagine, for example, two neighborhoods with high levels of deprivation, one that is characterized by social cohesion, trust, and a willingness to intervene when problems 
arise, and the second that is the opposite. An example of neighborhood-level strengths in the face of deprivation was demonstrated by residents of New York City apartment complexes that had been abandoned by their landlords and taken by the city for taxes. With the city's consent, a group of residents took over control of the complexes, developed management and rent-collection strategies, and operated the apartments successfully for some time (Saegert, 1996).

Similarly, it is not the case that neighborhood affluence is sufficient for fostering collective efficacy. Rather, it is easy to imagine affluent neighborhoods where people do not know their neighbors and have very little opportunity to interact and build trust and solidarity (e.g., high-rise condominiums, gated communities). It is also straightforward to identify how affluent areas mobilize other resources that may offset any reduction in local trust and reduce intergenerational contact with children, such as high-quality child care, organized after-school programs, interventions for high-risk youth, and a higher reserve of financial capital to be tapped as needed. Thus, while we anticipated significant variability in the levels of collective efficacy within both deprived and affluent neighborhoods, we hypothesized that collective efficacy would have a stronger effect on children's antisocial behavior in deprived neighborhood contexts.

We hypothesized that collective efficacy would exert a stronger effect in deprived neighborhoods as they often contain subsidized housing (e.g., council housing or housing projects) that are characterized by small living units. These residences are often overcrowded, which may lead children to spend more time outside their homes. Parental supervision may also be lower within high-deprivation neighborhoods as parents (often single parents) struggle to work long hours and balance child-care and work-force responsibilities. In short, children living in deprived neighborhoods are likely to spend more unsupervised time in their neighborhoods. Thus, the presence of invested adults (informal mechanisms of social control), combined with high levels of trust and solidarity among neighbors (social cohesion), may be more relevant in shaping children's antisocial behavior within deprived neighborhood contexts.

\section{The Present Study}

Children were participants in the Environmental Risk Longitudinal Twin Study (E-Risk Study), an epidemiological cohort of 2,232 children assessed prospectively at ages 5, 7 and 10. The design of the E-Risk Study is well suited for examining neighborhood-level effects on children's antisocial behavior. First, the E-Risk Study is a nationally representative sample of twins that represent the distribution of British families on the variables being studied in this article. Second, researchers assessed children's antisocial behavior prospectively on three occasions using multiple informants and standardized assessment criteria. Third, neighborhood-level characteristics were assessed via both census-level data and an independent neighborhood survey of residents living alongside the families in the ERisk Study; prior research has relied primarily on census-level data or has obtained information about both neighborhood features and the child's behavior through the same sole informant. Of note, the resolution of neighborhood assessments in this study is finer grained than that previously achieved. Respondents to our survey lived in the same postcode 
area as the E-Risk families; in Britain, a postcode area typically contains 15 households, with at most 100 households (e.g., typically a large apartment block; Office of National Statistics, 2008). Therefore, survey respondents who provided assessments of the children's neighborhoods were typically living on the same street or, often, within the same apartment block as the E-Risk families. Fourth, we included key family-level factors to control for endogeny, which is one of the main confounds in the interpretation of neighborhood-level research (Leventhal \& Brooks-Gunn, 2000).

Because families are not randomly selected into neighborhoods, the child's mother's and father's history of antisocial behavior may have influenced where the families chose to live. The concentration of antisocial behavior within families (Farrington, Jolliffe, Loeber, Stouthamer-Loeber, \& Kalb, 2001) and aggregation of crime within neighborhoods (Eck, Chainey, Cameron, Leitner, \& Wilson, 2005) is well established. Therefore, family-level information was used to control for possible selection effects on the observed relationship(s) between neighborhood factors and children's antisocial behavior. By including parents' history of antisocial behavior, we also controlled for two important causes of antisocial behavior: familial genetic loading and parents' environmental influences on their children's conduct (Moffitt et al., 2007). We also controlled for other key family-level factors (e.g., physical child maltreatment, domestic violence, and family socioeconomic disadvantage) that are heavily concentrated in deprived neighborhoods and have shown robust associations with children's antisocial behavior in prior research.

The analyses proceeded in four steps:

1. First, the developmental course of children's antisocial behavior was mapped with latent growth curve modeling. Based on prior research, we anticipated that antisocial behavior would decline between the ages of 5 and 10 for both male and female children.

2. Second, the developmental course of children's antisocial behavior was mapped across affluent versus deprived neighborhoods. We expected that children in deprived neighborhoods would have higher initial levels of antisocial behavior at school entry and slower rates of socialization away from antisocial behavior between the ages of 5 and 10 .

3. Third, we tested whether neighborhood collective efficacy was associated with initial levels of antisocial behavior or with change in antisocial behavior between the ages of 5 and 10 after controlling for neighborhood and family-level factors. We anticipated that neighborhood-level collective efficacy would be associated with lower levels of antisocial behavior at school entry and would also predict a faster rate of decline in antisocial behavior across time.

4. Fourth, we evaluated whether collective efficacy influenced children's development more strongly in deprived versus affluent neighborhoods. We hypothesized that collective efficacy would be more strongly related to children's antisocial behavior within deprived versus affluent neighborhoods and that collective efficacy might have a protective effect on children growing up in deprivation. 


\section{Method}

\section{Participants}

The E-Risk sample was drawn from a 1994-1995 birth register of twins born in England and Wales (Trouton, Spinath, \& Plomin, 2002). The sample was selected in 1999-2000, when 1,116 families with same-sex 5-year-old twins participated in home-visit assessments, forming the base cohort for the longitudinal E-Risk Study. Families drawn from the birth register were spread all across England and Wales and represented the full range of socioeconomic status in Britain. All families were English speaking, and the majority (93.7\%) of the families were White. Further sampling details are reported elsewhere (Moffitt, 2002). Briefly, a high-risk stratification strategy was used to replace any families lost to the original register at the time of birth due to selective nonresponse, and we included a further oversample to ensure sufficient numbers of children growing up in high-risk environments. The risk stratification was based on young maternal age at first birth. All statistical analyses of data from the E-Risk cohort are weighted back to the population on the basis of information about maternal age at first birth from the United Kingdom General Household Survey (Bennett, Javis, Rowlands, Singleton, \& Haselden, 1996). Thus, findings reported here related to neighborhood effects and antisocial behavior can be generalized to the larger population of British families with children born in the 1990s.

At the age-5 assessment, with parents' permission obtained during the home visit, questionnaires were posted to the children's teachers, who returned questionnaires for $94 \%$ of children. Two years later, a follow-up home visit was conducted when the children were 7 years old for $98 \%$ of the 1,116 E-Risk families, and teacher questionnaires were obtained for $91 \%$ of the 2,232 E-Risk twins (93\% of those followed up). A third follow-up home visit was conducted when the children were 10 years old for $96 \%$ of the 1,116 E-Risk families, and teacher questionnaires were obtained for $86.3 \%$ of the 2,232 E-Risk twins ( $90.1 \%$ of those followed up). The E-Risk Study received ethical approval from the Maudsley Hospital Ethics Committee.

Does the fact that the children in our sample are twins versus singletons limit the generalizability of our findings? A number of studies have shown that twins and singletons do not differ on their mean levels of behavioral problems (Gjone \& Novik, 1995; Kendler, Martin, Heath, \& Eaves, 1995; Moilanen et al., 1999; van den Oord, Koot, Boomsma, Verhulst, \& Orlebeke, 1995) and that the strength and direction of relationships between neighborhood-level factors and children's mental health outcomes are similar across singleton versus twin samples (Kim-Cohen, Moffitt, Caspi, \& Taylor, 2004). Thus, there was no a priori empirical reason to anticipate that findings regarding the relationship between neighborhood-level factors and antisocial behavior with twins would not generalize to singletons.

With that said, it is possible that children who are twins may follow a different developmental course of antisocial behavior. For example, the presence of a same-age sibling may influence the development of antisocial behavior by increasing opportunities for repeated conflict, or alternatively, frequent interaction with a same age sibling may accelerate the development of self-regulation and peer relationship skills through repeated 
exposure to negotiating conflict in same-age sibling interactions. As such, it will be interesting to observe whether twins in this sample demonstrate the same developmental pattern of decline in antisocial behavior that has been documented within population-based samples of singletons (Stanger et al., 1997). It is also the case that families of twins may experience unique social and economic pressures. Becoming a parent of twins (versus a singleton) is associated with a heavier caregiving burden and may create unique financial and parenting stressors as parents struggle to meet the demands of caring for two children (Spillman, 1984). Therefore, the unique pressures that families of twins may face leaves open the possibility that neighborhood-level factors may have differential effects on the antisocial behavior of twins versus singletons. Thus, while we assume that our findings will generalize to the general population of British families with children born in the 1990s, replication of findings from this study with singletons will be required.

\section{Measures}

Children's antisocial behavior was assessed with the Achenbach family of instruments (Achenbach, 1991a, 1991b). We combined mother interviews and teacher reports of children's behavior on the Aggression and Delinquency scales by summing the items from each rater (items scored from 0-2). The Antisocial Behavior Scale was administered when the children were age $5(M=23.0, S D=17.3, \mathrm{a}=.94$, range $=0-130.4, N=2,232)$, age 7 ( $M$ $=20.3, S D=17.2, a=.95$, range $=0-132.0, N=2,178)$, and age $10(M=19.5, S D=17.8$, $\mathrm{a}=.92$, range $=0-150.0, N=2,138)$.

Father's and mother's history of antisocial behavior was reported by the mothers when the children were 5 years old. Mothers were interviewed using the Young Adult Behavior Checklist (Achenbach, 1997), which was modified to obtain lifetime data. Full details of father's $(M=17.4, S D=18.0, \mathrm{a}=.95$, range $=0-88.0, N=2,214)$ and mother's $(M=12.7$, $S D=10.6, \mathrm{a}=.95$, range $=0-60.0, N=2,226$ ) history of antisocial behavior within this sample are reported elsewhere (Jaffee, Moffitt, Caspi, \& Taylor, 2003). A study of motherfather agreement about men's antisocial behavior in this sample showed that women provided reliable information about the behavior of their children's father (Caspi et al., 2001).

Physical child maltreatment was assessed separately for each twin at age 5 and age 7 by interviewing mothers with the standardized clinical interview protocol from the Child Development Project (Dodge, Pettit, Bates, \& Valente, 1995). ${ }^{1}$ Full details of the child physical maltreatment measure within this sample are reported elsewhere (Jaffee, Caspi, Moffitt, \& Taylor, 2004). There was definite evidence of physical child maltreatment for $5.0 \%$ of the sample. Examples of such maltreatment included being a victim of adjudicated assault by a teenaged sibling, being burned with matches, sustaining injuries (e.g., fractures) from neglectful or abusive parental care, or being formally registered with a social-services child protection team because of physical abuse.

\footnotetext{
${ }^{1}$ The interview protocol was designed to enhance mothers' comfort with reporting valid child maltreatment information, while also meeting researchers' legal and ethical responsibilities for reporting. Under the U.K. Children's Act (1989), our responsibility was to secure intervention if maltreatment was current and ongoing. Such intervention on behalf of E-Risk families was carried out with parental cooperation in all but one case.
} 
Adult domestic violence was assessed by the Conflict Tactics Scale (Straus, 1990) when the children were 5 years old. Mothers were asked about their own violence toward any partner and about any partners' violence toward them over the entire 5 years since the twins' birth. Mothers' reports were based on information about 12 acts of physical violence (items scored $0-1)$. The average adult domestic violence score was $1.83(S D=3.28, \alpha=.89$, range $=0-20$, $N=2,218$ ). Full details of the adult domestic violence measure in this sample are reported elsewhere (Koenen, Moffitt, Caspi, Taylor, \& Purcell, 2003).

Family socioeconomic disadvantage was assessed when the children were age 5 based on a count of six socioeconomic disadvantages, defined as follows: (a) head of household had no educational qualifications; (b) head of household was employed in an unskilled occupation or was not in the labor force; (c) total household gross annual income was less than $£ 10,000$; (d) family was receiving at least one government benefit, excluding disability benefit; (e) family housing was government subsidized; and (f) family had no access to a vehicle. The average socioeconomic disadvantage score was $1.38(S D=1.70, \mathrm{a}=.79$, range $=0-6, N=$ 2,232). Full details of this measure in this sample are reported elsewhere (Kim-Cohen et al., 2004).

Neighborhood deprivation versus affluence was assessed using A Classification of Residential Neighborhoods (ACORN), a geodemographic discriminator developed by CACI Information Services (1997) for use in commercial and policy studies conducted in Great Britain. CACI created ACORN using 1991 census data collected for the whole of Great Britain at the enumeration-district (ED) level, the smallest area at which census data are made available by the Office of National Statistics (each containing approximately 150 households). CACI identified 79 different items (e.g., age, educational qualifications, unemployment, single-parent status, housing tenure and dwelling type, and car availability) that were combined to give a comprehensive picture of socioeconomic differences among different areas. CACI used hierarchical cluster analysis to group EDs that share similar characteristics into 54 neighborhood types. The hierarchical clustering procedure resulted in the 54 neighborhood types being aggregated into six distinct and homogeneous ordinal categories. The six broad categories ranged from the most affluent neighborhoods in Britain, whose residents have high incomes, large single-family houses, and access to many amenities (ACORN Category 1; 16.7\% of E-Risk families), to the most deprived neighborhoods in Britain, which are dominated by government-subsidized housing estates whose residents who have low incomes and high rates of unemployment and are likely to be single parents (ACORN Category 6; 25.1\% of E-Risk families). Each family in our sample was matched to the ACORN code for its neighborhood via its postal code (Caspi, Taylor, Moffitt, \& Plomin, 2000). Results are presented for affluent (ACORN Categories 1-3) versus deprived (ACORN Categories 4-6) neighborhoods.

Neighborhood social-process measures were obtained via postal survey in 2003, when the E-Risk children were 8-9 years old. Questionnaires were sent to 15 households in the same postcode as each of the 1,116 families registered in the E-Risk Study, excluding the E-Risk family (addresses were identified from electoral roll records). ${ }^{2}$ As explained earlier, in Britain, a postcode area typically contains 15 households, with at most 100 households (e.g., large apartment block). Therefore, survey respondents were typically living on the same 
street or within the same apartment block as the children in our study. This type of postcodelevel resolution represents a marked advantage over many existing neighborhood studies in which much larger census tract or census block units of analysis are used. Our objective was to obtain multiple reporters (e.g., 2 or more) for each family's neighborhood (here defined to the street or apartment block level). Considering the fact that the typical response rate for neighborhood surveys is approximately $30 \%$ (Messner, Baumer, \& Rosenfeld, 2004), we mailed surveys to 15 households within each postcode unit. In total, 16,676 households were mailed the neighborhood questionnaire. The survey responses were anonymous; no identifying information was collected. Each survey was stamped with a code to link the response to its E-Risk family. Surveys were returned by an average of 3 respondents per neighborhood (range $=0-10$ respondents). We achieved at least three responses for $76 \%$ of target neighborhoods, at least two responses for $90 \%$, and at least one response for $97 \%$ of target neighborhoods (resulting in a total of 4,709 completed questionnaires). What this means is that multiple individuals living on the same street or in the same apartment block of the children in our study provided independent assessments of the neighborhoods in which the E-Risk children were growing up. Survey respondents were mainly women (60\%), and 68\% were between the ages of 25 and 65 years. The majority of respondents had lived in the neighborhood for more than 5 years (83\%), and only $1 \%$ of respondents had lived in the neighborhood for less than 1 year. The primary measures derived from the neighborhood survey are described in the following section.

Informal social control was represented by five items (Sampson et al., 1997). Residents were asked about the likelihood (coded from $4=$ very likely to $0=$ very unlikely) that their neighbors could be counted on to intervene in various ways if "children were skipping school and hanging out on a street corner," "children were spray-painting graffiti on a local building," "children were showing disrespect to an adult," "a fight broke out in front of [their] house," and "the fire station closest to [their] home was threatened with budget cuts." Social cohesion and trust were also represented by five items (Sampson et al., 1997). Respondents were asked how strongly they agreed (coded from $4=$ strongly agree to $0=$ strongly disagree) that "people around here are willing to help their neighbors," "this is a close-knit neighborhood," "people in this neighborhood can be trusted," "people in this neighborhood generally don't get along with each other" (reverse scored), and "people in this neighborhood do not share the same values" (reverse scored). Prior work has found that social cohesion and informal social control are tapping into the same latent construct. Thus, the creators of this measure have combined these scales into a summary measure labeled collective efficacy (Sampson et al., 1997). The collective efficacy scale used in this study is one of the most widely used assessment tools in neighborhood research and is currently considered the gold standard for measuring neighborhood-level social processes.

Each of the 10 items were standardized and then averaged to create a collective efficacy total score $(M=-0.07, S D=0.54$, range $=$ from -2.06 to $1.63, N=2,176)$. The aggregatelevel reliability of the collective efficacy scale was very high $(\alpha=.88)$, defined as $\Sigma\left[\tau_{00} /\left(\tau_{00}\right.\right.$ $\left.\left.+\sigma^{2} / N_{j}\right)\right] / \mathrm{J}$, the average of neighborhood-specific reliabilities across the set of $\mathbf{J}$ postcodes $(N$

\footnotetext{
${ }^{2}$ The source of the electoral records containing addresses for individuals living in same postcode as the E-Risk families was the Web site www.192.com.
} 
$=1,185)$. Thus, neighborhood reliability is not the same as an individual-level Cronbach's alpha; rather, it is a function of (a) the sample size $(N)$ in each of the $j$ neighborhoods and (b) the proportion of the total variance that is between neighborhoods $\left(\tau_{00}\right)$ relative to the amount that is within neighborhoods $\left(\sigma^{2}\right)$. A reliability of .88 means that we capture with high precision the mean differences across neighborhoods in collective efficacy (see Raudenbush \& Sampson, 1999). Collective efficacy ratings obtained via postal survey were also positively correlated with mother's collective efficacy ratings gathered during the age-7 in-home visit, $r=.30$ (1079), $p<.001$. The intraclass correlation (ICC), which indexes the agreement between reports from available respondents within each neighborhood, fell within the moderate to high range for neighborhood surveys (ICC = .29). An ICC value of .29 means that almost a third of the variation in collective efficacy resides between postcodes; this value exceeds what is typically reported for cognate measures in other neighborhood studies (Browning \& Cagney, 2002; Cook, Shobaba, \& Serdar, 1997; Raudenbush \& Sampson, 1999). ICCs infrequently exceed 20 (Snijders \& Bosker, 1999). We note, however, that interpretation of the ICC is problematic - even low values do not mean there is a lack of independence within areas (Roberts, 2007).

Neighborhood problems were measured using 10 items indexing disorder and crime in the neighborhood. Residents were asked whether they saw the following things as a problem in their neighborhood (coded as $0=$ No, not a problem, $1=$ Yes, somewhat of a problem, $2=$ Yes, a big problem): "Vandals who do things like damage phone boxes, smash street lamps, break windows, or paint graffiti on walls?" "Litter, broken glass, rubbish in public places?" "Run down buildings, abandoned cars, wastelands, or vacant shop fronts?" "People being drunk and unruly in public?" "People selling or using drugs?" "Groups of young people hanging out and causing trouble?" "Women and girls risk being harassed if they go out by themselves after dark?" "Muggings, robberies, or assaults on people?" "Cars or trucks getting stolen or broken into?" "Homes getting broken into or burgled?" Each of the 10 items was standardized and then averaged to create a neighborhood problems total score ( $M$ $=0.09, S D=0.60$, range $=$ from -0.82 to $2.25, N=2,176)$. Similar to the collective efficacy scale, the aggregate-level reliability of the neighborhood problems scale was very high $(a=$. 90), and the intraclass correlation fell within the moderate to high range for neighborhood surveys $(\mathrm{ICC}=.37)$.

\section{Statistical Analyses}

Analyses proceeded in four steps. First, we mapped developmental change in children's antisocial behavior between the ages of 5 and 10 using latent growth curve analyses (LGCA). LGCA models summarize information from multiple occasions into relatively few parameters (McArdle \& Epstein, 1987) and are now common in developmental research (Kim \& Cicchetti, 2006). Consistent with prior longitudinal research with singletons, we anticipated that antisocial behavior in the majority of children would decline between the ages of 5 and 10 .

LGCA was conducted within a structural equation modeling (SEM) framework (see Figure 1 ), where the observed variables (ASB $[\mathrm{t}]$ ) are the product of latent intercepts $\left(y_{0}\right)$ with unit weights $(=1)$, latent slopes $\left(y_{1}\right)$ with weights $(A[t]=\alpha[0], \alpha[2], \alpha[5])$, and individual error 
terms (e[t]). The initial level and slope are assumed to be random variables with fixed means $\left(\mu_{0}, \mu_{1}\right)$ but random variances $\left(\sigma_{0}^{2}, \sigma_{1}^{2}\right)$ and covariances $\left(\sigma_{0,1}^{2}\right)$ (McArdle \& Nesselroade, 2003). The structural model depicted in Figure 1 can also be represented as a random coefficients model or hierarchical linear model (HLM) where occasions are nested within individuals (Raudenbush \& Bryk, 1992). The SEM and HLM approaches both provide estimates of the fixed and random effects; the random effects, or variability across individual-level estimates, become the dependent variables in subsequent models.

Second, we tested whether children in affluent versus deprived neighborhoods differed on initial levels of antisocial behavior at school entry or on rates of decline in antisocial behavior between the ages of 5 and 10 . Models were tested separately for males and females.

Third, we tested whether neighborhood-level collective efficacy was predictive of children's initial levels of antisocial behavior at school entry or the rate of change in antisocial behavior between the ages of 5 and 10. We also tested for an association between collective efficacy and levels of antisocial behavior at ages 7 and 10. Models controlled for neighborhood problems, family-level factors (parental history of antisocial behavior, physical child maltreatment, domestic violence, and family socioeconomic disadvantage), and sex.

Fourth, multiple-group SEM models were applied to test whether collective efficacy had a stronger effect on children's antisocial behavior in deprived versus affluent neighborhoods. Again, models controlled for neighborhood problems, family-level factors, and sex.

Models were fitted in Mplus Version 4.2 (Muthén \& Muthén, 1998-2008) using maximum likelihood estimation. Missing data were handled through full information maximum likelihood procedure (Raykov, 2005). Missing data presented a minimal threat to the results due to high retention rates in the E-Risk Study (over 95\% response rate across occasions). We evaluated all SEM models using recommended fit indices, including the root-meansquare error of approximation (RMSEA), where values $<.08$ indicate acceptable fit and values $<.05$ indicate good fit; confirmatory fit index (CFI), where estimates $>.90$ indicate acceptable fit and values $>.95$ indicate good fit, and the standardized root-mean-square residual (SRMR), where values <.08 are considered acceptable (Hu \& Bentler, 1999; McDonald \& Ho, 2002). Statistical analyses were complicated by the fact that the E-Risk Study contained two children from each family. Therefore, the COMPLEX option in Mplus was used to compute adjusted standard error estimates and correct for the nonindependence of observations due to the fact that children in our study were nested within families.

\section{Results}

\section{Analysis 1. Does Children's Antisocial Behavior Decline Between the Ages of 5 and 10?}

LGCA findings are presented in Table 1 and illustrate two main points. First, on average, children showed a decline in antisocial behavior between the ages of 5 and 10 (decreasing 0.66 points on the CBCL Antisocial Behavior Scale per year). This finding held for both males $\left(\mathrm{y}_{1}=-.52\right)$ and females $\left(\mathrm{y}_{1}=-.78\right)$. There was a significant change in model fit 
between the no-growth and linear-growth models for male-only $\left(\Delta \chi^{2}=39.5 / \Delta d f=3, p<\right.$. $001, \mathrm{RMSEA}=.04, \mathrm{CFI}=.99, \mathrm{SRMR}=.04)$ and female-only $\left(\Delta \chi^{2}=59.8 / \Delta d f=3, p<.001\right.$, RMSEA $=.03, \mathrm{CFI}=.99, \mathrm{SRMR}=.02)$ samples, indicating that a linear versus no-growth model was supported for both males and females.

Second, the amount of variance around both the level and slope parameters was statistically significant, indicating that children in the E-Risk Study varied significantly on their (a) initial level of antisocial behavior at school entry, and (b) rate of change in antisocial behavior across childhood. These two parameters characterized children's development of antisocial behavior from ages 5 to 10 and are the dependent variables in all subsequent analyses.

\section{Analysis 2. Does Children's Developmental Course of Antisocial Behavior Differ Across Deprived versus Affluent Neighborhoods?}

As shown in Figure 2, children in deprived versus affluent neighborhoods were significantly elevated on antisocial behavior at each age. The parameter estimates and model fit indices from the multiple-group model displayed in Table $2 \mathrm{a}$ and Table $2 \mathrm{~b}$, respectively, illustrate two main points. First, children in deprived versus affluent neighborhoods had higher levels of antisocial behavior at school entry $\left(\mathrm{y}_{0}=21.61 \mathrm{vs.} 19.01, p<.01\right)$ and slower rates of decline in their antisocial behavior problems between the ages of 5 and $10\left(\mathrm{y}_{1}=-.54\right.$ vs. - . $78, p<.01) .{ }^{3}$ Second, constraining the developmental growth parameters (level and slope) across deprived versus affluent neighborhoods resulted in a significant loss in model fit $\left(\Delta \chi^{2}\right.$ $=12.5 / \Delta d f=2, p<.01$, Model 2 vs. Model 1 ) indicating that children in deprived versus affluent neighborhoods followed a different developmental course of antisocial behavior.

The difference in the developmental patterns of antisocial behavior was most pronounced between extreme neighborhood groups. Results from a multiple-group growth model comparing children in the most deprived (ACORN Category 6) versus the most affluent (ACORN Category 1) neighborhoods produced significant differences in initial levels of antisocial behavior ( $\mathrm{y}_{0}=23.81$ vs. 19.70 , respectively; $\left.p<.001\right)$ and in the rate of decline in antisocial behavior between the ages of 5 and 10 ( $\mathrm{y}_{1}=-.44$ vs. -.91 , respectively; $p<.001$ ).

All multiple-group analyses were completed separately for females versus males. Females in deprived $(n=712)$ versus affluent $(n=402)$ neighborhoods had higher levels of antisocial behavior at school entry $\left(\mathrm{y}_{0}=19.10\right.$ vs. $\left.15.30, p<.001\right)$ and slower rates of decline in their antisocial behavior problems between the ages of 5 and $10\left(\mathrm{y}_{1}=-.69\right.$ vs. $\left.-.85, p<.01\right)$.

Males in deprived $(n=702)$ versus affluent $(n=372)$ neighborhoods also had higher levels of antisocial behavior at school entry $\left(\mathrm{y}_{0}=24.15 \mathrm{vs.} 22.88, p<.01\right)$ and slower rates of decline in their antisocial behavior problems between the ages of 5 and $10\left(y_{1}=-39\right.$ vs. - . $70, p<.001)$.

\footnotetext{
${ }^{3}$ The genetic and environmental architecture of the developmental parameters of antisocial behavior was the same across different neighborhoods. Looking at the intercept, the monozygotic twin (MZ) versus dizogotic twin (DZ) correlations were .80 versus .43 in affluent neighborhoods and .80 versus .38 in deprived neighborhoods. Looking at the slope, the MZ versus DZ correlations were .51 versus .25 in affluent neighborhoods and .51 versus .21 in deprived neighborhoods.
} 


\section{Analysis 3. Does Neighborhood Collective Efficacy Predict Children's Developmental Course of Antisocial Behavior?}

We entered neighborhood-level collective efficacy into the SEM model displayed in Figure 1 by regressing children's level and slope antisocial behavior factors on ratings of neighborhood collective efficacy. Results from this analysis indicated that neighborhoodlevel collective efficacy was negatively related to children's initial levels of antisocial behavior $\left(\gamma_{01}=-0.10, p<.01\right)$; children living in neighborhoods with higher levels of collective efficacy had lower levels of antisocial behavior at school entry. There was also a trend towards neighborhood-level collective efficacy predicting how quickly children's antisocial behavior declined between the ages of 5 and 10; children in neighborhoods with higher levels of collective efficacy demonstrated a more rapid decrease in antisocial behavior across childhood (standardized $\gamma_{11}=-0.09, p=.10$. Model fit was as follows: CFI $=.98$, RMSEA $=.07$, SRMR $=.02$.

Next, neighborhood- and family-level covariates were entered into the model. The results from the full structural model are presented in Table 3 and illustrate four main findings. First, the relationship between collective efficacy and children's initial levels of antisocial behavior held after we controlled for neighborhood problems, mother's and father's history of antisocial behavior, physical child maltreatment, exposure to domestic violence, family socioeconomic disadvantage, and sex (standardized $\gamma_{01}=-0.07, p=.01$ ). This model represented a good fit to the data $(\mathrm{CFI}=.99, \mathrm{RMSEA}=.03$, SRMR $=.01)$, which offers assurance for interpreting the parameter estimates.

Second, a number of family level factors independently predicted children's antisocial behavior at school entry, including father's and mother's histories of antisocial behavior, physical child maltreatment, exposure to domestic violence, family socioeconomic disadvantage, and being male. Together, these factors explained approximately $28 \%$ of the variance in the latent antisocial behavior level factor. Third, we found that the trend toward a relationship between collective efficacy and children's rate of decline in antisocial behavior did not hold after controlling for neighborhood and family-level factors. Fourth, only mother's history of antisocial behavior independently predicted how quickly a child's antisocial behavior declined between the ages of 5 and 10. Together the factors explained only $4 \%$ of the variance in the latent antisocial behavior slope factor. Constraining parameter estimates to be equal across sex did not result in a significant change in model fit $\left(\Delta \chi^{2}=1.2 / \Delta d f=2, p=.55\right)$, indicating that there were no sex interactions in our analyses.

A sensitivity analysis was conducted to test whether collective efficacy may have exerted a stronger influence on children's antisocial behavior across development. Although there was a significant bivariate association between collective efficacy and children's latent intercepts of antisocial behavior at ages 5,7, and 10, the relationship between collective efficacy and children's antisocial behavior became nonsignificant at ages 7 and 10 once key covariates were entered into the model. 


\section{Analysis 4: Does Neighborhood Collective Efficacy have a Stronger Effect on Children in Deprived versus Affluent Neighborhoods?}

In this section, we discuss whether the effect of collective efficacy on the development of antisocial behavior is stronger in deprived versus affluent neighborhoods. If so, this would suggest that neighborhood collective efficacy has a protective effect on children growing up in deprivation. As shown in Table 4, neighborhood deprivation and collective efficacy did not necessarily go hand in hand. Although the mean levels of collective efficacy were significantly higher in affluent $(M=0.12, S D=0.44$, range $=$ from -1.97 to 1.43$)$ versus deprived $(M=-0.18, S D=0.56$, range $=$ from -2.06 to 1.63$)$ neighborhoods, there was significant overlap in the distributions. In fact, one of the most deprived neighborhoods in our sample (ACORN Category 6) had the highest average rating of collective efficacy ( $M=$ 1.63). The descriptive information displayed in Table 4 also illustrates that children in deprived versus affluent neighborhoods were exposed to significantly more neighborhood problems and, as expected, were elevated on a host of family-level factors. Cohen's $d$, which indexes the standardized mean differences across affluent versus deprived neighborhoods, revealed medium effect sizes $(0.58-0.77)$ for neighborhood-level factors and small to medium effect sizes $(0.13-0.68)$ for family-level factors. The following analysis controls for all of the risk factors listed in Table 4.

The multiple-group SEM shown in Figure 3 was fitted to test whether neighborhood collective efficacy had a stronger effect on children's initial levels $\left(\gamma_{01}\right)$ or rate of decline $\left(\gamma_{11}\right)$ of antisocial behavior across deprived versus affluent neighborhoods. Model 1 allowed the parameter estimates $\left(\gamma_{01}, \gamma_{11}\right)$ to be freely estimated across deprived versus affluent neighborhoods. Estimates for Model 1 are provided in Figure 3 and illustrate three main findings. First, there was a significant relationship between collective efficacy and initial levels of antisocial behavior in deprived neighborhoods only $\left(\gamma_{01}=-.10, p<.01\right)$. Second, there was no relationship between collective efficacy and the rate of decline in antisocial behavior in either deprived or affluent neighborhoods. Third, Model 2 constrained the relationship between neighborhood collective efficacy and initial levels of antisocial behavior to be equal across affluent versus deprived neighborhoods; when this constraint was added, there was a significant increase in model misfit as indexed by the chi-square statistic $\left(\Delta \chi^{2}=6.4 / \Delta d f=1, p=.04\right)$, indicating that the relationship between collective efficacy and initial levels of antisocial behavior was not equivalent across deprived versus affluent neighborhoods. However, when the slope parameter was constrained to be equal across deprived versus affluent neighborhoods, there was no significant change in model fit $\left(\Delta \chi^{2}=1.4 / \Delta d f=1, p=.24\right)$, indicating that neighborhood deprivation versus affluence did not moderate the relationship between collective efficacy and the rate of change in antisocial behavior. Moreover, constraining parameter estimates to be equal across sex in these models did not result in a significant change in model fit $\left(\Delta \chi^{2}=2.4 / \Delta d f=6, p=.88\right)$, indicating that there were no sex interactions in our analyses.

To summarize, the relationship between collective efficacy and children's antisocial behavior at school entry was moderated by whether they lived in a deprived versus affluent neighborhood. For children in affluent neighborhoods, collective efficacy did not predict antisocial behavior at school entry, whereas for children in deprived neighborhoods, higher 
levels of collective efficacy predicted significantly lower levels of antisocial behavior at school entry: In deprived neighborhoods, the estimate was both significantly different than zero and significantly different from the estimate obtained for children in affluent neighborhoods. Neighborhood deprivation versus affluence did not moderate the relationship between collective efficacy and how children's antisocial behavior changed between the ages of 5 and 10; estimates were not significantly different than zero, and estimates in deprived versus affluent neighborhoods did not differ significantly from each other.

\section{Discussion}

A deprived neighborhood can be a harmful place for children to grow up. However, our findings suggest that some deprived neighborhoods also contain important assets—such as collective efficacy - that may have a protective effect on children's antisocial behavior. Results from this study take us beyond what we currently know about the relationship between neighborhood-level factors and children's antisocial behavior in three ways.

\section{Children Growing Up in Deprived versus Affluent Neighborhoods Follow a Different Developmental Course of Antisocial Behavior}

Children in deprived versus affluent neighborhood contexts had higher levels of antisocial behavior at school entry and slower rates of decline in antisocial behavior between the ages of 5 and 10. This finding held for both males and females and is consistent with prior research that has documented a relationship between neighborhood deprivation and problem behaviors in adolescence (for reviews, see Leventhal \& Brooks-Gunn, 2000 and Ingoldsby \& Shaw, 2002). However, what this study adds is an illustration of how the developmental course of antisocial behavior may differ across deprived versus affluent neighborhood contexts during childhood. Decline in antisocial behavior during childhood is recognized as a normative, as well as an adaptive, developmental process (Tremblay, 2000). The prognosis for children who exhibit persistent involvement in antisocial behavior through this developmental window is poor (see Moffitt, 2006). Our findings indicate that neighborhood deprivation may be an important marker of which children follow a persistent developmental trajectory of antisocial behavior, thus providing a new impetus for studying the mechanisms through which neighborhood characteristics affect children's development in deprived contexts.

\section{Neighborhood-Level Collective Efficacy is a Robust Predictor of Children's Antisocial Behavior at School Entry}

Children in neighborhoods with high levels of collective efficacy had lower levels of antisocial behavior at school entry; this relationship was robust and held after we controlled for neighborhood problems, children's parents' history of antisocial behavior, and a host of family-level factors that may have otherwise accounted for the relationship between neighborhood factors and children's antisocial behavior. This finding also held for both males and females, and, to our knowledge, ours is one of the first studies to document a relationship between independent assessments of collective efficacy and antisocial behavior 
in childhood. However, a similarly robust relationship was not found between collective efficacy and children's antisocial behavior at later ages.

There was also a trend for children's antisocial behavior to decline more quickly in neighborhoods with higher levels of collective efficacy. However, this relationship did not hold once neighborhood problems and family-level factors were entered into the model (as shown on Table 3). Therefore, in the end, we did not observe the hypothesized relationship between neighborhood collective efficacy and a faster rate of decline in antisocial behavior through childhood, and moreover, we did not find evidence to support an increasing influence of collective efficacy on children's levels of antisocial behavior across middle childhood. Nonetheless, it will be important to test whether neighborhood collective efficacy predicts the course of antisocial behavior as we follow the E-Risk children into adolescence, when neighborhood factors may be more prominent in explaining developmental change.

\section{Neighborhood-Level Collective Efficacy is Related to Children's Antisocial Behavior in Deprived Neighborhoods Only}

Children in deprived neighborhoods followed a more compromised developmental course of antisocial behavior. However, our results suggest that neighborhood collective efficacy may work to protect children growing up in deprivation. Within deprived neighborhoods, collective efficacy was related to lower levels of antisocial behavior among children at school entry; this effect was not true in affluent neighborhoods. These findings inform the growing body of research on protective factors and antisocial behavior and are consistent with prior research among high-risk male adolescents, in whom higher functioning neighborhood social processes have been associated with less severe developmental trajectories of antisocial behavior (Gorman-Smith, Tolan, \& Henry, 2000). In sum, beyond showing that deprived neighborhoods and low levels of neighborhood collective efficacy are risk factors for children's antisocial behavior, these results illustrate that neighborhood collective efficacy can operate as a protective factor in deprived neighborhood contexts.

The mounting body of evidence documenting the relationship between neighborhood deprivation and poor child outcomes (Cubbin, LeClere, \& Smith, 2000; Gordon-Larsen, Nelson, Page, \& Popkin, 2006; Kohen, Brooks-Gunn, Leventhal, \& Hertzman, 2002; Winkleby \& Cubbin, 2003; Winslow \& Shaw, 2007) is concerning given that in the year 2000 one in five children in the United States lived in neighborhoods where at least $20 \%$ of the population lived in deprivation, with the latest estimates indicating that over 1.3 million children have fallen into deprivation since that time (Mather \& Rivers, 2006). Given the significant number of children who are influenced by deprivation, there is a pressing need to identify child, family, and neighborhood-level factors with the potential to improve the outcomes for children growing up in deprived contexts.

Findings from this study indicate that levels of informal social control and cohesion within deprived neighborhoods may help to buffer the harmful effects of deprivation on children. Given the young age of our sample, it is likely that children's direct experiences of the neighborhood are limited and that the influence of neighborhood-level factors occurs indirectly via effects on parents. As children move through their primary school years and begin to have more direct exposure to members of the community and institutions (e.g., 
schools, youth center), neighborhood-level effects are likely to be transmitted both directly and indirectly, through a series of complex and age-dependent pathways (Ingoldsby \& Shaw, 2002). However, prior research in adolescence has been mixed. For example, the random assignment of families to low-poverty neighborhoods-with higher levels of parental reported collective efficacy-in the Moving to Opportunity (MTO) housing mobility experiment was reported to have adverse effects on adolescent males' arrests for property crimes, but beneficial effects for most types of crime among adolescent females (Kling, Ludwig, \& Katz, 2005). Thus, while our results suggest that neighborhood collective efficacy may be particularly important in the primary school years, it may be the case that waiting until adolescence to alter neighborhood contexts may be too late, particularly for males. Experimental studies with both children and adolescents are required to fully test this theory and isolate the precise mechanisms through which neighborhood-level social processes influence children's development.

\section{Limitations and Implications}

This study has clear limitations. First, because neighborhood collective efficacy was assessed only once, when the E-Risk children were 7.5 years old, the stability of collective efficacy over the 5 years of the study could not be estimated.

Second, we were unable to control for school-level effects in these analyses. It is possible that neighborhoods that are rated high on collective efficacy were also neighborhoods that contained more effective schools. Future research that integrates neighborhood- and schoollevel effects is required to determine the most relevant context(s) for child development (Cook, Herman, Phillips, \& Settersten, 2002) and test whether school contexts mediate the relationship between neighborhood factors and child outcomes.

Third, our research focused on only one child outcome, antisocial behavior. Yet, childhood antisocial behavior co-occurs with a number of other mental health indicators. Moreover, neighborhood-level factors, including collective efficacy, are known to influence a wide range of child outcomes, including intelligence (Sampson, Sharkey, \& Raudenbush, 2007), early mental health problems (Xue et al., 2005), childhood obesity and asthma (Chen \& Paterson, 2006; Cohen et al., 2006). Thus, future research that examines multiple child outcomes within the same cohort is required.

Fourth, consistent with prior research, the relationship between children's antisocial behavior at school entry and neighborhood collective efficacy $(r=-0.10)$ was small (Leventhal \& Brooks-Gunn, 2000). Three considerations need to be kept in mind when interpreting small effect sizes in neighborhood research: (a) the majority of prior researchincluding this study - has reported only independent versus total effects of neighborhood factors on child and adolescent outcomes (Duncan \& Raudenbush, 1999); (b) ecometrics is a relatively young science, which means that there is significant room for improvement in the development of tools for assessing neighborhood settings; and (c) small effect sizes can have large implications for prevention when the costs associated with the outcome are large (McCartney \& Rosenthal, 2000) - as is the case with early-onset and persistent antisocial behavior. Rosenthal (1994) provided one of the best examples of a small effect size, the effect of aspirin on the prevention of heart attacks $(r=.03)$, that was deemed to have great 
importance due to the relatively cheap costs of treatment (pennies a day for aspirin) versus the high costs associated with the outcome (life or death).

Fifth, the majority of research to date has been based on U.S. samples. Neighborhood boundaries in Britain are more porous than the highly race- and class-stratified neighborhoods in the United States. Thus, the effects of collective efficacy may be distributed differently within and across adjoining neighborhoods in Britain. There was also minimal residential mobility in our British sample compared with what is typically documented in U.S. samples; $86 \%$ of the E-Risk children lived in the same local area throughout the study. High rates of residential stability in Britain may enhance collective efficacy. Future work is required to validate the assessment of collective efficacy across cultures, and coordinated research efforts focused on neighborhood factors and antisocial behavior are now underway (Social Contexts of Pathways in Crime Network, n.d.).

Sixth, antisocial behavior was assessed on only three occasions. Therefore, we were limited in how accurately we could characterize the functional form of children's developmental course of antisocial behavior over time. Continued assessment of this sample will provide us with the opportunity to assess antisocial behavior during the young-adolescent period and map the development of antisocial behavior using the latest generation of trajectory-based models (Muthén, 2004; Nagin, 2005).

With these limitations in mind, the implications of this study for public policy can be noted. The majority of interventions for children's antisocial behavior target the child and/or the family, with relatively little attention paid to neighborhood contexts. Our findings suggest that community affluence and also community-level social processes-namely, collective efficacy-may serve as protective factors for children as they enter school. Such community characteristics may be prime candidates for population-level intervention efforts. Potential strategies for building and enhancing collective efficacy within communities have been suggested, including bolstering participation in voluntary organizations to develop better trust and social relationships, building community social organizations such as local civic organizations and clubs, and creating "community health profiles" that allow communities to monitor their well-being over time. Community-level interventions are rarely tried in the area of antisocial behavior but may be more cost-effective and pragmatic than the difficult prospects of individual intervention.

\section{Acknowledgments}

The E-Risk Study is supported by the U.K Medical Research Council (G9806489 and G0100527) and the Social Contexts of Pathways in Crime (SCOPIC) Network. This research was also supported by a visiting fellowship from the Economic and Social Research Council awarded to Candice L. Odgers. Terrie E. Moffitt and Avshalom Caspi are Royal-Society Wolfson Research Merit Award holders.

We are grateful to the study mothers and fathers, the twins, and the twins' teachers for their participation. Our thanks to Thomas Achenbach for his kind permission to adapt the Child Behavior Checklist and to members of the E-Risk team for their dedication and hard work. We also thank Jill Collins and Paul Langston at CACI for their geo-coding assistance and Group Sigma for their assistance with the neighborhood postal survey. 


\section{References}

Achenbach, TM. Manual for the Child Behavior Checklist/4-18 and 1991 Profile. University of Vermont Department of Psychiatry; Burlington, VT: 1991a.

Achenbach, TM. Manual for the Teacher's Report Form and 1991 Profile. University of Vermont Department of Psychiatry; Burlington, VT: 1991b.

Achenbach, TM. Manual for the Young Adult Self Report and Young Adult Behavior Checklist. University of Vermont Department of Psychiatry; Burlington, VT: 1997.

Bennett, N.; Javis, L.; Rowlands, O.; Singleton, N.; Haselden, L. Living in Britain: Results from the General Household Survey. Her Majesty’s Stationery Office; London: 1996.

Broidy LM, Nagin DS, Tremblay RE, Bates JE, Brame B, Dodge KA, et al. Developmental trajectories of childhood disruptive behaviors and adolescent delinquency: A six-site, cross-national study. Developmental Psychology. 2003; 39:222-245. [PubMed: 12661883]

Bronfenbrenner U. Ecology of the family as a context for human-development. Research perspectives. Developmental Psychology. 1986; 22:723-742.

Brooks-Gunn, J. Neighborhood poverty: Context and consequences for children. Russell Sage Foundation; New York: 1997.

Browning CR. The span of collective efficacy: Extending social disorganization theory to partner violence. Journal of Marriage and the Family. 2002; 64:833-850.

Browning CR, Cagney KA. Neighborhood structural disadvantage, collective efficacy, and self-rated physical health in an urban setting. Journal of Health and Social Behavior. 2002; 43:383-399. [PubMed: 12664672]

CACI Information Services. ACORN user guide. CACI; London: 1997.

Cairns RB, Cairns BD, Neckerman HJ, Ferguson LL, Gariepy JL. Growth and aggression: Childhood to early adolescence. Developmental Psychology. 1989; 25:320-330.

Calkins SD. Origins and outcomes of individual differences in emotion regulation. Monographs of the Society for Research in Child Development. 1994; 59:2-3. Serial No. 240.

Caspi A, Taylor A, Moffitt TE, Plomin R. Neighborhood deprivation affects children's mental health: Environmental risks identified in a genetic design. Psychological Science. 2000; 11:338-342. [PubMed: 11273396]

Caspi A, Taylor A, Smart M, Jackson J, Tagami S, Moffitt TE. Can women provide reliable information about their children's fathers? Cross-informant agreement about men's lifetime antisocial behaviour. Journal of Child Psychology and Psychiatry and Allied Disciplines. 2001; 42:915-920.

Chen E, Paterson LQ. Neighborhood, family, and subjective socioeconomic status: How do they relate to adolescent health? Health Psychology. 2006; 25:704-714. [PubMed: 17100499]

Children's Act of 1989. Chapter 41. Acts of the U.K. Parliament;

Cohen DA, Farley TA, Mason K. Why is poverty unhealthy? Social and physical mediators. Social Science and Medicine. 2003; 57:1631-1641. [PubMed: 12948572]

Cohen DA, Finch BK, Bower A, Sastry N. Collective efficacy and obesity: The potential influence of social factors on health. Social Science and Medicine. 2006; 62:769-778. [PubMed: 16039767]

Cook, T.; Shobaba, S.; Serdar, D. Capturing social process for testing mediational models of neighborhood effects. In: Brooks-Gunn, J.; Duncan, GJ.; Aber, L., editors. Neighborhood poverty: Policy implications in studying neighborhoods. Russell Sage; New York: 1997. p. 94-119.

Cook TD, Herman MR, Phillips M, Settersten RA. Some ways in which neighborhoods, nuclear families, friendship groups, and schools jointly affect changes in early adolescent development. Child Development. 2002; 73:1283-1309. [PubMed: 12146748]

Coté SM, Vaillancourt T, LeBlanc JC, agin DS, Tremblay RE. The development of physical aggression from toddlerhood to pre-adolescence: A nation wide longitudinal study of Canadian children. Journal of Abnormal Child Psychology. 2006; 34:68-82.

Cubbin C, LeClere FB, Smith GS. Socioeconomic status and injury mortality: Individual and neighbourhood determinants. Journal of Epidemiology and Community Health. 2000; 54:517-524. [PubMed: 10846194] 
Cummins S, Curtis S, Diez-Roux AV, Macintyre S. Understanding and representing "place" in health research: A relational approach. Social Science \& Medicine. 2007; 65:1825-1838. [PubMed: 17706331]

Dodge KA, Pettit GS, Bates JE, Valente E. Social information-processing patterns partially mediate the effect of early physical abuse on later conduct problems. Journal of Abnormal Psychology. 1995; 104:632-643. [PubMed: 8530766]

Duncan GJ, Raudenbush SW. Assessing the effects of context in studies of child and youth development. Educational Psychologist. 1999; 34:29-41.

Duncan, GJ.; Raudenbush, SW. Neighborhoods and adolescent development: How can we determine the links?. In: Booth, A.; Crouter, AC., editors. Does it take a village? Community effects on children, adolescents, and families. Erlbaum; Mahwah, NJ: 2001. p. 105-136.

Earls F, Carlson M. The social ecology of child health and well-being. Annual Review of Public Health. 2001; 22:143-166.

Eck, JE.; Chainey, S.; Cameron, JG.; Leitner, M.; Wilson, RE. Mapping crime: Understanding hot spots. National Institute of Justice; Washington, DC: 2005.

Eisenberg N, Guthrie IK, Fabes RA, Shepard S, Losoya S, Murphy BC, et al. Prediction of elementary school children's externalizing problem behaviors from attention and behavioral regulation and negative emotionality. Child Development. 2000; 71:1367-1382. [PubMed: 11108101]

Farrington DP, Jolliffe D, Loeber R, Stouthamer-Loeber M, Kalb LM. The concentration of offenders in families, and family criminality in the prediction of boys' delinquency. Journal of Adolescence. 2001; 24:579-596. [PubMed: 11676506]

Fergusson DM, Horwood JL, Ridder EM. Show me the child at seven: The consequences of conduct problems in childhood for psychosocial functioning in adulthood. Journal of Child Psychology and Psychiatry. 2005; 46:837-849. [PubMed: 16033632]

Gjone H, Novik TS. Parental ratings of behavior problems: A twin and general-population comparison. Journal of Child Psychology and Psychiatry and Allied Disciplines. 1995; 36:1213-1224.

Gordon-Larsen P, Nelson MC, Page P, Popkin BM. Inequality in the built environment underlies key health disparities in physical activity and obesity. Pediatrics. 2006; 117:417-424. [PubMed: 16452361]

Gorman-Smith D, Tolan PH, Henry DB. A developmental-ecological model of the relation of family functioning to patterns of delinquency. Journal of Quantitative Criminology. 2000; 16:169-198.

Hawkins, JD.; Catalano, RF. Communities that care. Jossey-Bass; San Francisco: 1992.

$\mathrm{Hu}$ L, Bentler PM. Cutoff criteria for fit indexes in covariance structure analysis: Conventional criteria versus new alternatives. Structural Equation Modeling. 1999; 6:1-55.

Ingoldsby EM, Shaw DS. Neighborhood contextual factors and early-starting antisocial pathways. Clinical Child and Family Psychology Review. 2002; 5:21-55. [PubMed: 11993544]

Ingoldsby EM, Shaw DS, Winslow E, Schonberg M, Gilliom M, Criss MM. Neighborhood disadvantage, parent-child conflict, neighborhood peer relationships, and early antisocial behavior problem trajectories. Journal of Abnormal Child Psychology. 2006; 34:303-319. [PubMed: 16705498]

Jaffee SR, Caspi A, Moffitt TE, Taylor A. Physical maltreatment victim to antisocial child: Evidence of an environmentally mediated process. Journal of Abnormal Psychology. 2004; 113:44-55. [PubMed: 14992656]

Jaffee SR, Moffitt TE, Caspi A, Taylor A. Life with (or without) father: The benefits of living with two biological parents depend on the father's antisocial behavior. Child Development. 2003; 74:109-126. [PubMed: 12625439]

Kaplan, GA. Social epidemiologic approaches to the causes and consequences of depression: Do we need to think about depressing environments?; Paper presented at the University of Michigan Depression Center Colloquium Series; Ann Arbor. 2007, April;

Kendler KS, Martin NG, Heath AC, Eaves LJ. Self-report psychiatric symptoms in twins and their nontwin relatives: Are twins different? American Journal of Medical Genetics. 1995; 60:588-591. [PubMed: 8825903] 
Kim J, Cicchetti D. Longitudinal trajectories of self-system processes and depressive symptoms among maltreated and nonmal-treated children. Child Development. 2006; 77:624-639. [PubMed: 16686792]

Kim-Cohen J, Caspi A, Moffitt TE, Harrington H, Milne BJ, Poulton R. Prior juvenile diagnoses in adults with mental disorder: Developmental follow-back of a prospective-longitudinal cohort. Archives of General Psychiatry. 2003; 60:709-717. [PubMed: 12860775]

Kim-Cohen J, Moffitt TE, Caspi A, Taylor A. Genetic and environmental processes in young children's resilience and vulnerability to socioeconomic deprivation. Child Development. 2004; 75:651-668. [PubMed: 15144479]

Kling JR, Ludwig J, Katz LF. Neighborhood effects on crime for female and male youth: Evidence from a randomized housing voucher experiment. Quarterly Journal of Economics. 2005; 120:87130.

Koenen KC, Moffitt TE, Caspi A, Taylor A, Purcell S. Domestic violence is associated with environmental suppression of IQ in young children. Development and Psychopathology. 2003; 15:297-311. [PubMed: 12931829]

Kohen DE, Brooks-Gunn J, Leventhal T, Hertzman C. Neighborhood income and physical and social disorder in Canada: Associations with young children's competencies. Child Development. 2002; 73:1844-1860. [PubMed: 12487498]

Kratzer L, Hodgins S. A typology of offenders: A test of Moffitt's theory among males and females from childhood to age 30. Criminal Behaviour and Mental Health. 1999; 9:57-73.

Leventhal T, Brooks-Gunn J. The neighborhoods they live in: The effects of neighborhood residence on child and adolescent outcomes. Psychological Bulletin. 2000; 126:309-337. [PubMed: 10748645]

Leventhal T, Brooks-Gunn J. Children and youth in neighborhood contexts. Current Directions in Psychological Science. 2003; 12:27-31.

Macintyre S, Ellaway A, Cummins S. Place effects on health: How can we conceptualise, operationalise and measure them? Social Science \& Medicine. 2002; 55:125-139. [PubMed: 12137182]

Mather, M.; Rivers, KL. The concentration of negative child outcomes in low-income neighborhoods. Annie E. Casey Foundation; Baltimore: 2006.

McArdle JJ, Epstein D. Latent growth curves within developmental structural equation models. Child Development. 1987; 58:110-133. [PubMed: 3816341]

McArdle, JJ.; Nesselroade, JR. Growth curve analysis in contemporary psychological research. In: Schinka, JA.; Velicer, WF., editors. Handbook of psychology: Research methods in psychology. Wiley; New York: 2003. p. 447-480.

McCartney K, Rosenthal R. Effect size, practical importance, and social policy for children. Child Development. 2000; 71:173-180. [PubMed: 10836571]

McDonald RP, Ho MR. Principles and practice in reporting structural equation analyses. Psychological Methods. 2002; 7:64-82. [PubMed: 11928891]

Messner SF, Baumer EP, Rosenfeld R. Dimensions of social capital and rates of criminal homicide. American Sociological Review. 2004; 69:882-903.

Moffitt TE. Teen-aged mothers in contemporary Britain. Journal of Child Psychology and Psychiatry. 2002; 43:727-742. [PubMed: 12236608]

Moffitt, TE. Life-course-persistent and adolescent-limited antisocial behavior. In: Cicchetti, D.; Cohen, DJ., editors. Developmental psychopathology: Vol. 3. Risk, disorder, and adaptation. Wiley; New York: 2006. p. 570-598.

Moffitt TE, Arseneault L, Jaffee SR, Kim-Cohen J, Koenen KC, Odgers CL, et al. DSM-V conduct disorder: Research needs for an evidence base. Journal of Child Psychology and Psychiatry and Allied Disciplines. 2007; 49:3-33.

Moffitt TE, Caspi A, Harrington H, Milne BJ. Males on the life-course-persistent and adolescencelimited antisocial pathways: Follow-up at age 26 years. Development and Psychopathology. 2002; 14:179-207. [PubMed: 11893092] 
Moilanen I, Linna SL, Ebeling H, Kumpulainen K, Tamminen T, Piha J, et al. Are twins' behavioural/ emotional problems different from singletons'? European Child and Adolescent Psychiatry. 1999; 8(Suppl. 8):62-67. [PubMed: 10654135]

Morenoff JD, Sampson RJ, Raudenbush SW. Neighborhood inequality, collective efficacy, and the spatial dynamics of urban violence. Criminology. 2001; 39:517-559.

Muthén, B. Latent variable analysis: Growth mixture modeling and related techniques for longitudinal data. In: Kaplan, D., editor. Handbook of quantitative methodology for the social sciences. Sage Publications; Newbury Park, CA: 2004. p. 345-368.

Muthén, B.; Muthén, LK. Mplus. Muthén \& Muthén; Los Angeles: 1998-2008.

Nagin D, Tremblay RE. Trajectories of boys' physical aggression, opposition, and hyperactivity on the path to physically violent and nonviolent juvenile delinquency. Child Development. 1999; 70:1181-1196. [PubMed: 10546339]

Nagin, DS. Group-based modeling of development. Harvard University Press; Cambridge: 2005.

Odgers CL, Caspi A, Broadbent JM, Dickson NP, Hancox R, Harrington H, et al. Prediction of adult health burden by conduct problem subtypes in males. Archives of General Psychiatry. 2007a; 64:476-484. [PubMed: 17404124]

Odgers CL, Milne B, Caspi A, Crump R, Poulton R, Moffitt TE. Predicting prognosis for the conductproblem boy: Can family history help? Journal of the American Academy of Child and Adolescent Psychiatry. 2007b; 46:1240-1249. [PubMed: 17885565]

Odgers CL, Moffitt TE, Caspi A, Broadbent JM, Dickson NP, Hancox R, et al. Female and male antisocial trajectories: From childhood origins to adult outcomes. Development and Psychopathology. 2008; 20:673-716. [PubMed: 18423100]

Office of National Statistics. Beginners' guide to UK geography. Author; London: 2008. Retrieved April 23, 2009, from http://www.statistics.gov.uk/geography/beginners_guide.asp

Piquero AR, Daigle LE, Gibson C, Leeper Piquero N, Tibbetts SG. Are life-course-persistent offenders at risk for adverse health outcomes? Journal of Research in Crime and Delinquency. 2007; 44:185-207.

Raudenbush, SW.; Bryk, AS. Hierarchical linear models. Sage Publications; London: 1992.

Raudenbush SW, Sampson RJ. Ecometrics: Toward a science of assessing ecological settings, with application to the systematic social observation of neighborhoods. Sociological Methodology. 1999; 29:1-41.

Raykov T. Analysis of longitudinal studies with missing data using covariance structure modeling with full-information maximum likelihood. Structural equation modeling: A multidisciplinary journal. 2005; 12:493-505.

Roberts, JK. Group dependency in the presence of small intraclass correlation coefficients: An argument in favor of not interpreting the ICC; Paper presented at the American Educational Research Association Conference; Chicago, Illinois. 2007, April;

Rosenthal, R. Parametric measures of effect size. In: Cooper, H.; Hedges, LV., editors. The handbook of research synthesis. Russell Sage Foundation; New York: 1994. p. 231-244.

Saegert, S. Growing the seeds of strength in high-risk urban neighborhoods; Paper presented at the annual meeting of the American Psychological Association; Toronto, ON, Canada. 1996, August;

Sampson RJ. The neighborhood context of well-being. Perspectives in Biology and Medicine. 2003; 46:S53-S64. [PubMed: 14563074]

Sampson RJ, Morenoff JD, Earls F. Beyond social capital: Spatial dynamics of collective efficacy for children. American Sociological Review. 1999; 64:633-660.

Sampson RJ, Morenoff JD, Gannon-Rowley T. Assessing “neighborhood effects": Social processes and new directions in research. Annual Review of Sociology. 2002; 28:443-478.

Sampson RJ, Raudenbush SW. Systematic social observation of public spaces: A new look at disorder in urban neighborhoods. American Journal of Sociology. 1999; 105:603-651.

Sampson RJ, Raudenbush SW, Earls F. Neighborhoods and violent crime: A multilevel study of collective efficacy. Science. Aug 15.1997 277:918-924. [PubMed: 9252316] 
Sampson RJ, Sharkey P, Raudenbush SW. Durable effects of concentrated disadvantage on verbal ability among African American children. Proceedings of the National Academies of Science of the United States of America. 2007; 105:845-852.

Snijders, T.; Bosker, R. Multilevel analysis: An introduction to Basic and advanced multilevel modeling. Sage Publications; London: 1999.

Network for the Study of Social Contexts of Pathways in Crime Network (SCOPIC). Social Contexts of Pathways in Crime (SCOPIC) Cambridge Network. n.d.Retrieved April 23, 2009, from the Economic and Social Research Council Web site at http://www.esrcsocietytoday.ac.uk/ ESRCInfoCentre/research/networks/SCOPIC.aspx

Spillman JR. Double exposure: Coping with newborn twins at home. Midwife, Health Visitor, and Community Nurse. 1984; 20:92-94.

Stanger C, Achenbach TM, Verhulst FC. Accelerated longitudinal comparisons of aggressive versus delinquent syndromes. Development and Psychopathology. 1997; 9:43-58. [PubMed: 9089123]

Straus, MA. Measuring intrafamily conflict and violence: The Conflict Tactics (CT) Scales. In: Straus, MA.; Gelles, RJ., editors. Physical violence in American families: Risk factors and adaptations to violence in 8,145 families. Transaction; New Brunswick, NJ: 1990. p. 403-424.

Tremblay RE. The development of aggressive behaviour during childhood: What have we learned in the past century? International Journal of Behavioral Development. 2000; 24:129-141.

Tremblay, RE. When children's social development fails. In: Keating, D.; Hertzman, C., editors. Developmental health and the wealth of nations: Social, biological, and educational dynamics. Guilford Press; New York: 2004. p. 55-71.

Tremblay, RE.; Nagin, DS. The developmental origins of physical aggression in humans. In: Tremblay, RE.; Hartup, WW.; Archer, J., editors. Developmental origins of aggression. Guilford Press; New York: 2005. p. 83-106.

Trouton A, Spinath FM, Plomin R. Twins Early Development Study (TEDS): A multivariate, longitudinal genetic investigation of language, cognition, and behavior problems in childhood. Twin Research. 2002; 5:444-448. [PubMed: 12537874]

van den Oord EJ, Koot HM, Boomsma DI, Verhulst FC, Orlebeke JF. A twin-singleton comparison of problem behavior in 2- to 3-year-olds. Journal of Child Psychology and Psychiatry and Allied Disciplines. 1995; 36:449-458.

Wiesner M, Kim HK, Capaldi DM. Developmental trajectories of offending: Validation and prediction to young adult alcohol use, drug use, and depressive symptoms. Development and Psychopathology. 2005; 17:251-270. [PubMed: 15971769]

Winkleby MA, Cubbin C. Influence of individual and neighborhood socioeconomic status on mortality among Black, Mexican-American, and White women and men in the United States. Journal of Epidemiology and Community Health. 2003; 57:444-452. [PubMed: 12775792]

Winslow EB, Shaw DS. Impact of neighborhood disadvantage on overt behavior problems during early childhood. Aggressive Behavior. 2007; 33:207-219. [PubMed: 17444527]

Xue Y, Leventhal T, Brooks-Gunn J, Earls FJ. Neighborhood residence and mental health problems of 5- to 11-year-olds. Archives of General Psychiatry. 2005; 62:554-563. [PubMed: 15867109] 


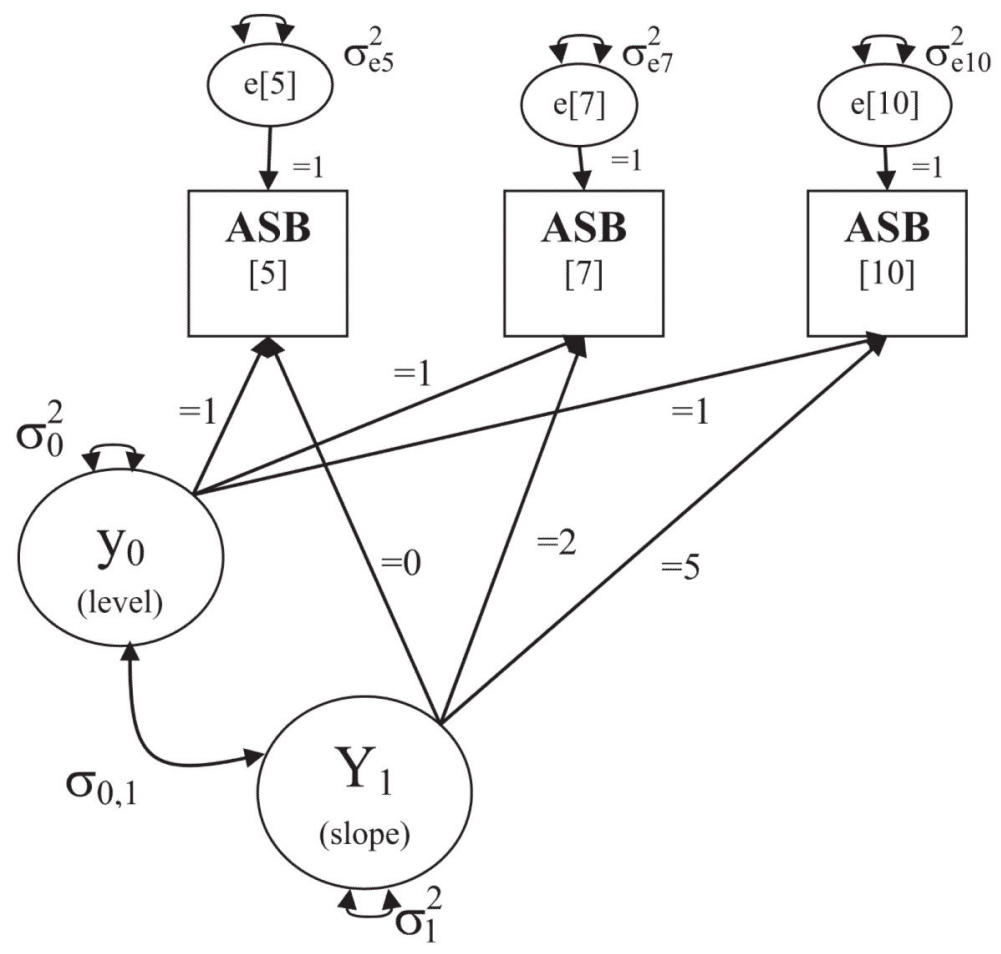

Figure 1.

Structural representation of latent growth curve model. Observed variables are depicted as squares: ASB[5], ASB[7], ASB[10] = antisocial behavior problem score at age 5, age 7, and age 10. Latent variables are represented as circles: $y_{0}=$ fixed effect estimate of the population mean for level of antisocial behavior; $y_{1}=$ fixed effect estimate of the population mean for the slope of antisocial behavior between the ages of 5 and 10. Random effects variables are represented as follows: $\sigma_{0,1}=$ the covariance between the level and the slope; $\sigma_{0}^{2}=$ the variance of the level; $\sigma_{1}^{2}=$ the variance of the slope; $\sigma_{\mathrm{e} 5}^{2}, \sigma_{\mathrm{e} 7}^{2}$ and $\sigma_{\mathrm{e} 10}^{2}=$ error terms. Error terms $\sigma_{\mathrm{e} 5}^{2}, \sigma_{\mathrm{e} 7}^{2}$, and $\sigma_{\mathrm{e} 10}^{2}$ were constrained to be equal across ages 5, 7, and 10 . 


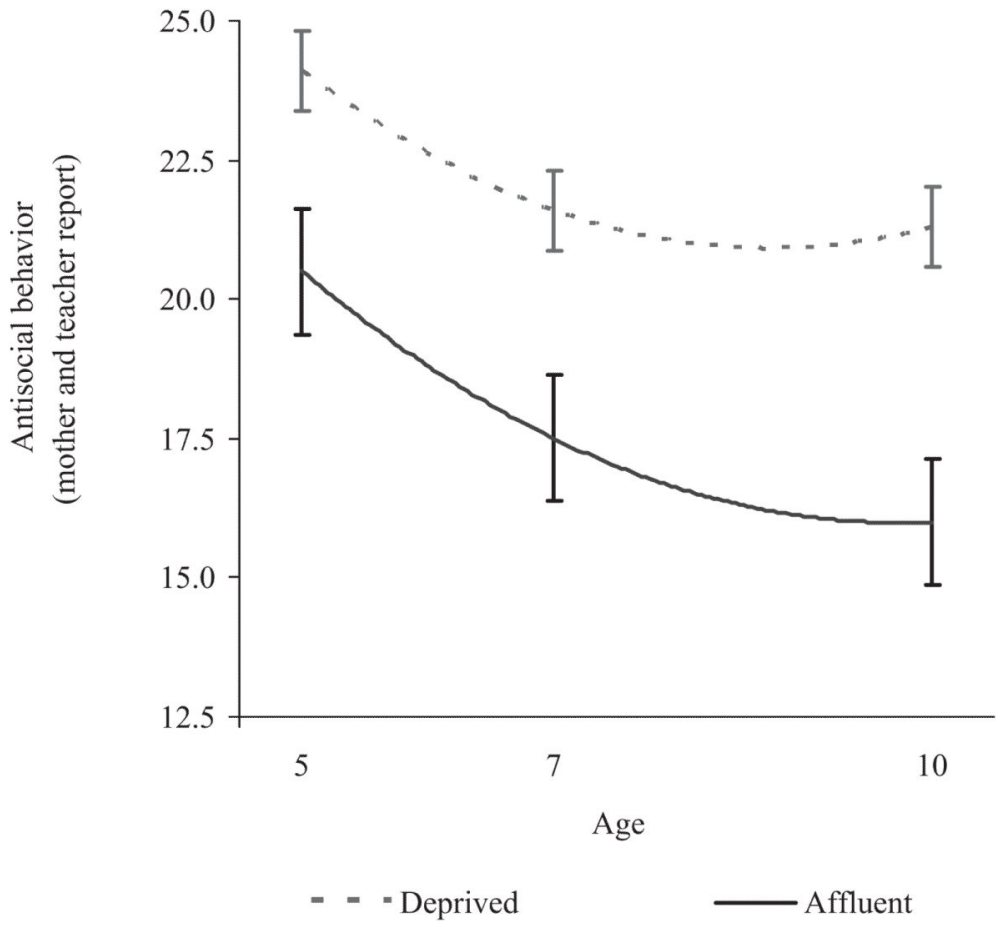

Figure 2.

Mean levels of antisocial behavior problems between the ages of 5 and 10 years by affluent ( $n=774)$ versus deprived neighborhoods $(n=1,414)$. Vertical lines represent $95 \%$ confidence intervals of the means at each assessment age. Trend lines connecting each assessment age within neighborhood type have been smoothed. 
Group 1: Affluent neighborhoods $(\mathrm{n}=774)$

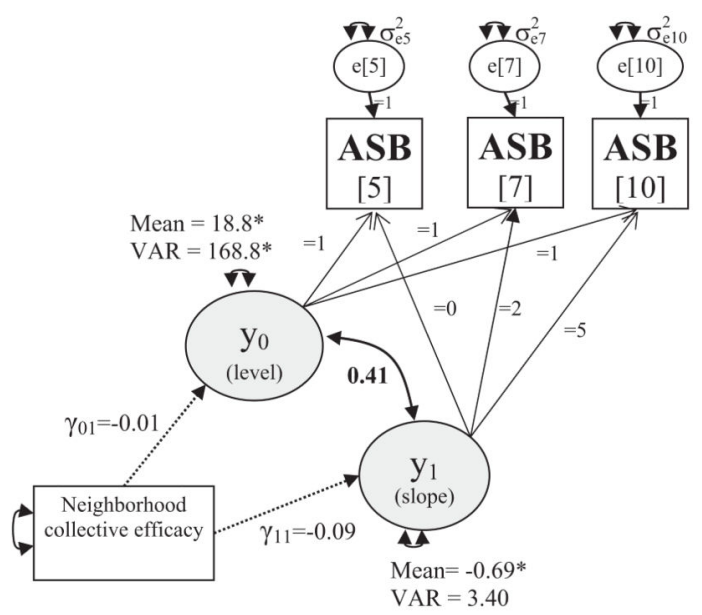

Group 2: Deprived neighborhoods $(n=1414)$

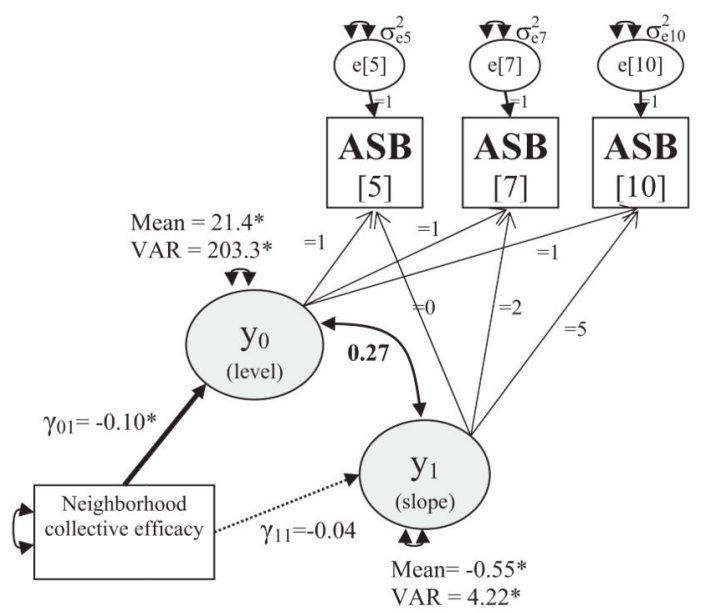

Figure 3.

Regression of children's initial level and slope of antisocial behavior on neighborhood collective efficacy by affluent versus deprived neighborhoods. Group 1: Affluent neighborhoods ( $n=774)$; Group 2: Deprived neighborhoods $(n=1,414)$. Observed variables are depicted as squares: ASB[5], ASB[7], ASB[10]= antisocial behavior problem score at age 5 , age 7 , and age 10 . Latent variables are represented as circles; $y_{0}=$ fixed effect estimate of the population mean for level of antisocial behavior, $\mathrm{y}_{1}=$ fixed effect estimate of the population mean for the slope of antisocial behavior between the ages of 5 and $10 ; \sigma_{\mathrm{e} 5}^{2}$, $\sigma_{\mathrm{e} 7}^{2}$, and $\sigma_{\mathrm{e} 10}^{2}=$ error term. Path estimates $\left(\gamma_{01}, \gamma_{11}\right)$ are adjusted to account for neighborhood problems, family history of antisocial behavior, physical child maltreatment, exposure to domestic violence, family socioeconomic disadvantage, and sex. Therefore, paths $\gamma_{01}$ and $\gamma_{11}$ represent independent effects of neighborhood collective efficacy on the level and slope, net of other covariates in the model. VAR = variance. ${ }^{*} p<.05$. 


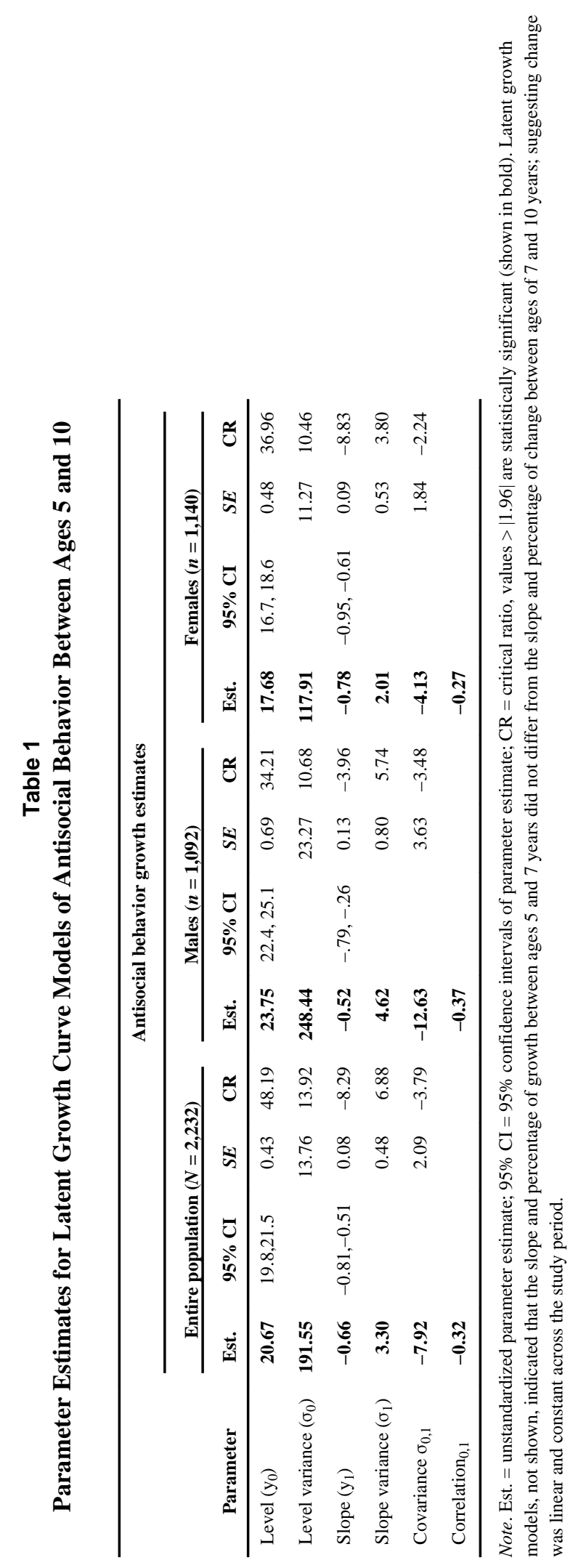

Dev Psychol. Author manuscript; available in PMC 2014 October 29. 
Table 2a

Multiple Group Latent Growth Curve Model by Deprived Versus Affluent Neighborhoods

\begin{tabular}{|c|c|c|c|c|c|c|c|c|}
\hline \multirow[b]{2}{*}{ Parameter } & \multicolumn{4}{|c|}{$\begin{array}{l}\text { Children in affluent neighborhoods } \\
\qquad(n=774)\end{array}$} & \multicolumn{4}{|c|}{$\begin{array}{l}\text { Children in deprived neighborhoods } \\
(n=1,414)\end{array}$} \\
\hline & Est. & $95 \% \mathrm{CI}$ & SE & CR & Est. & $95 \% \mathrm{CI}$ & SE & $\mathbf{C R}$ \\
\hline Level $\left(\mathrm{y}_{0}\right)$ & 19.01 & $17.7,20.4$ & 0.69 & 27.68 & 21.61 & $20.5,22.7$ & 0.55 & 39.30 \\
\hline Level variance $\left(\sigma_{0}\right)$ & 164.86 & & 21.95 & 7.51 & 202.73 & & 18.72 & 10.83 \\
\hline Slope $\left(\mathrm{y}_{1}\right)$ & -0.78 & $-1.02,-0.53$ & 0.12 & -6.30 & -0.54 & $-0.75,-0.34$ & 0.10 & -5.21 \\
\hline Slope variance $\left(\sigma_{1}\right)$ & 2.09 & & 0.77 & 2.72 & 4.16 & & 0.65 & 6.56 \\
\hline Covariance $\sigma_{0,1}$ & -8.41 & & 3.41 & -2.47 & -7.31 & & 2.60 & -2.81 \\
\hline Correlation $_{0,1}$ & -0.45 & & & & -0.25 & & & \\
\hline
\end{tabular}

Note. Est. $=$ unstandardized parameter estimate $; 95 \% \mathrm{CI}=95 \%$ confidence intervals of parameter estimate; $\mathrm{CR}=$ critical ratio, values $>11.961$ are statistically significant (shown in bold). RMSEA = root-mean-square error of approximation; CFI = confirmatory fit index; SRMR $=$ standardized root-mean-square residual. 
Table 2b

Model Fit Statistics

\begin{tabular}{|c|c|c|c|c|c|c|c|}
\hline \multirow[b]{2}{*}{ Parameter } & \multicolumn{5}{|c|}{ Model fit indices } & \multicolumn{2}{|c|}{ Likelihood ratio test } \\
\hline & $X^{2}$ & $d f$ & RMSEA & CFI & SRMR & $\begin{array}{c}\text { Model } \\
\text { comparison }\end{array}$ & $\Delta X^{2} / \Delta d f$ \\
\hline Model 1: Free & 15.3 & 7 & 0.03 & 0.99 & 0.03 & - & - \\
\hline Model 2: Constrained & 27.8 & 9 & 0.04 & 0.98 & 0.06 & 2 vs. 1 & $12.5 / 2$ \\
\hline
\end{tabular}

Note RMSEA = root-mean-square error of approximation; $\mathrm{CFI}=$ confirmatory fit index; SRMR = standardized root-mean-square residual. 
Table 3

\section{Structural Equation Modeling (SEM) Parameter Estimates Predicting Children's Level} and Slope of Antisocial Behavior

\begin{tabular}{|c|c|c|c|c|c|}
\hline \multirow[b]{2}{*}{ Parameter } & \multicolumn{5}{|c|}{ SEM parameter estimate } \\
\hline & Unstand. est. & $95 \% \mathrm{CI}$ & $S E$ & CR & Stand. est. \\
\hline $\mathrm{y}_{0}$ (antisocial behavior level) & 9.74 & $8.45,11.04$ & 0.66 & 14.73 & \\
\hline $\mathrm{y}_{1}$ (antisocial behavior slope) & -0.58 & $-0.83,-0.32$ & 0.13 & -4.39 & \\
\hline Covariance $\left(\mathrm{y}_{0}, \mathrm{y}_{1}\right)$ & -7.44 & $-11.20,-3.68$ & 1.92 & -3.88 & -.30 \\
\hline \multicolumn{6}{|l|}{ Predicting antisocial behavior level $\left(\mathrm{y}_{0}\right)$} \\
\hline$\gamma_{01} \mid$ Collective efficacy & -2.03 & $-3.68,-0.45$ & 0.82 & -2.48 & -.07 \\
\hline$\gamma_{02} \mid$ Neighborhood problems & 0.47 & $-1.07,2.02$ & 0.78 & 0.60 & .02 \\
\hline$\gamma_{03} \mid$ Fathers' antisocial behavior & 0.13 & $0.06,0.20$ & 0.04 & 3.81 & .16 \\
\hline$\gamma_{04} \mid$ Mothers' antisocial behavior & 0.47 & $0.36,0.59$ & 0.06 & 8.08 & .33 \\
\hline$\gamma_{05} \mid$ Physical child maltreatment & 4.22 & $2.38,6.06$ & 0.94 & 4.50 & .15 \\
\hline$\gamma_{06}$ Domestic violence & 0.60 & $0.25,0.94$ & 0.17 & 3.45 & .13 \\
\hline$\gamma_{07} \mid$ Family socioeconomic disadvantage & 0.85 & $0.28,1.41$ & 0.29 & 2.92 & .09 \\
\hline$\gamma_{08} \mid \operatorname{Sex}(0=$ female, $1=$ male $)$ & 5.81 & $4.34,7.27$ & 0.75 & 7.76 & .21 \\
\hline \multicolumn{6}{|l|}{ Predicting antisocial behavior slope (y1) } \\
\hline$\gamma_{11} \mid$ Collective efficacy & -0.18 & $-0.57,0.21$ & 0.20 & -0.91 & -.05 \\
\hline$\gamma_{12} \mid$ Neighborhood problems & -0.07 & $-0.40,0.26$ & 0.17 & -0.42 & -.02 \\
\hline$\gamma_{13} \mid$ Fathers' antisocial behavior & 0.001 & $-0.01,0.02$ & 0.01 & 0.15 & .01 \\
\hline$\gamma_{14} \mid$ Mothers' antisocial behavior & -0.04 & $-0.06,-0.02$ & 0.01 & -3.43 & .19 \\
\hline$\gamma_{15} \mid$ Physical child maltreatment & 0.08 & $-0.30,0.44$ & 0.19 & 0.40 & .02 \\
\hline$\gamma_{16} \mid$ Domestic violence & 0.07 & $-0.01,0.16$ & 0.04 & 1.80 & .12 \\
\hline$\gamma_{17} \mid$ Family socioeconomic disadvantage & 0.07 & $-0.07,0.20$ & 0.07 & 0.92 & .05 \\
\hline$\gamma_{18} \mid \operatorname{Sex}(0=$ female, $1=$ male $)$ & 0.25 & $-0.06,0.55$ & 0.16 & 1.58 & .07 \\
\hline
\end{tabular}

Note. Unstand. est. = unstandardized parameter estimate; Stand. est. = standardized parameter estimate; $95 \% \mathrm{CI}=95 \%$ confidence intervals of parameter estimate; $S E=$ standard error; $\mathrm{CR}=$ critical ratio (unstandardized estimated/SE); $\gamma 01-\gamma 08=$ regression of random intercept (level) of antisocial behavior at school entry on covariates; $\gamma 11-\gamma 18=$ regression of random slope of antisocial behavior between ages 5 and 10 years on covariates. Statistically significant estimates $(<.05$ level $)$ are in bold. Model fit $=X^{2}=(11, N=2,232)=30.78$, confirmatory fit index $=0.99$, rootmean-square error of approximation $=0.03$, standardized root-mean-square residual $=.01$. 
Table 4

Measure Descriptions and Standardized Mean Differences Across ACORN-Defined Affluent Versus Deprived Neighborhoods

\begin{tabular}{|c|c|c|c|c|c|c|}
\hline \multirow[b]{2}{*}{ Variable } & \multicolumn{2}{|c|}{$\begin{array}{c}\text { Children in affluent } \\
\text { neighborhoods } \\
(n=774) \\
\end{array}$} & \multicolumn{2}{|c|}{$\begin{array}{c}\text { Children in deprived } \\
\text { neighborhoods } \\
(n=\mathbf{1 , 4 1 4}) \\
\end{array}$} & \multicolumn{2}{|c|}{$\begin{array}{c}\text { Between-group comparison of } \\
\text { affluent vs. deprived } \\
\text { neighborhoods } \\
\end{array}$} \\
\hline & Mean & $S D$ & Mean & $S D$ & Cohen's $d$ & $p$ \\
\hline Antisocial behavior, age 5 & 20.5 & 16.0 & 24.1 & 17.7 & 0.21 & $<.001$ \\
\hline Antisocial behavior, age 7 & 17.5 & 15.5 & 21.6 & 17.8 & 0.24 & $<.001$ \\
\hline Antisocial behavior, age 10 & 16.0 & 14.8 & 21.3 & 19.0 & 0.30 & $<.001$ \\
\hline Collective efficacy & 0.12 & 0.44 & -0.18 & 0.56 & 0.58 & $<.001$ \\
\hline Neighborhood problems & -0.19 & 0.44 & 0.23 & 0.61 & 0.77 & $<.001$ \\
\hline Fathers' antisocial behavior & 12.47 & 14.24 & 19.76 & 18.90 & 0.42 & $<.001$ \\
\hline Mothers' antisocial behavior & 10.17 & 8.90 & 13.93 & 11.13 & 0.36 & $<.001$ \\
\hline Physical child maltreatment & 0.18 & 0.47 & 0.25 & 0.56 & 0.13 & $<.01$ \\
\hline Domestic violence & 1.11 & 2.40 & 2.21 & 3.60 & 0.34 & $<.001$ \\
\hline Family socioeconomic disadvantage & 0.65 & 1.23 & 1.74 & 1.79 & 0.68 & $<.001$ \\
\hline Sex (\% male $)$ & 48.1 & & 49.6 & & 0.03 & $=0.48$ \\
\hline
\end{tabular}

Note. The six A Classification of Residential Neighborhoods (ACORN)-defined neighborhood groups were dichotomized into affluent versus deprived categories following a six-group structural equation modeling analysis testing for differences between intercepts, slopes, and covariate effects across neighborhood groups. $S D=$ standard deviation; Cohen's d = $\mathrm{M}_{1}-\mathrm{M}_{2} / \sigma_{\text {pooled }}$, where $\mathrm{M}_{1}=$ the mean of the deprived neighborhood group, $\mathrm{M}_{2}=$ the mean of the affluent neighborhood group, and $\sigma_{\text {pooled }}=$ the pooled standard deviation of the two groups. 